Panel Session

\title{
Digital Canvas: Artists and Designers in the 2D/3D Marketplace
}

\author{
Chair: \\ Rachel Carpenter, Cinematrix \\ Speakers: \\ John Derry, Chromaset \\ Claire Barry, SuperMac Technology \\ Peter Conn, Homer and Associates \\ Vibeke Sorensen, California Institute of the Arts
} alive.

I'm Rachel Carpenter, and this mike seems to be really

The films that you've been watching on the screen are from the Animation Screening Room, which is really hot this year We've got a lot of wonderful pieces. It's in the Sheraton, just as you walk in from the Hines, and you'll see signs there. There are three viewing environments. Right at the beginning, there is a cafe environment where you can sit down with food and just watch things. There's a room next to it with monitors and then there's a large room with rear projection, large screen, lots of seats. There are schedules available. At any time you can watch two different things.

I decided to put this panel together when I was working at a computer graphics school for artists and designers. People were always asking, "Well, where are the jobs? What kind of work is there, and why should I bother with computers?" So I got these people together who have been in the business, in various aspects, for many years, and have found their own way. They will tell you their stories and give you an idea of how to look for things.

There are some very specific ideas. Other people seem to have been having the same thoughts because the education committee put together this wonderful Volume 23, Careers Handbook, and I suggest that you get it. It's in the education booth as you come into the Hines, there are all those booths well, the one on the end, toward the entrance, is called Space, they have up the student artwork. Volume 23 has categories of different kinds of jobs, career profiles, colleges and universities which are organized by topic first, if it's art and design or engineering or other types of signs or medical or whatever, and then by state.

Then they have about the job search process. There's also a questionnaire at the end, which the people who put this together really urge everyone to fill out the questionnaire and send it in. It's a tremendous amount of information. They are available at the booth or you can call up ACM and order one. It's Volume 23.

I also want to tell you about another really good opportunity for artists. I happen to be the United States Representative for Prix Ars Electronica; it's a competition in Austria for computer art, animation \& music. They have significant cash prizes. So if you're interested in entering that after this is over, give me your address and I'll see that you get entry forms for that. You can also call me in California at 415 . 892-8254.

Also, you've seen a lot of things while you've been here at SIGGRAPH and I want to let you know that everybody can participate. I started going to SIGGRAPH in 1980 when it was in Seattle.

I'm not sure quite how many people were there then, but it was probably something like 17,000, and when I was SIGGRAPH '85 Art Show administrator in San Francisco, there were 27,000 people attending the conference. It keeps on growing because people are interested and because the industry is growing. You can contribute too. If you have an idea, write it up, present it as a course, panel or submit to someone on the committee.

The Animation Screening Room shows works representative of what is going on in computer graphics, over $50 \%$ of the work in there is science related. Some of that's medical, some engineering, geology, molecular modeling various things. The are lists there; you can look and see types of job categories.

A large group is composed of works that could be considered commercial production. Architecture, art and character animation form a smaller amount of what is being produced in computer graphics. So search out those other areas. There are many fields out there. This handbook will help you and we hope you get some ideas from our panelists.

The amount of material in the Screening Room is about 8 $1 / 2$ hours. It's taken a lot of work to put that together. There were 21 hours of work submitted to the film show jury and all of that had to be gone through many times.

I want to let you know also that afterwards we have a breakout room for people who want to get together. I know we have a lot of artists and designers here, besides the panelists, and there may be some of you who are looking for - maybe you have jobs for people or maybe you're just interested in listening. So we will find out where that breakout room is going to be and I'll tell you at the end.

A: $\mathrm{J}$ as in Jones.

CARPENTER: Okay, the breakout room is going to be in $J$ Room - as in H, I, J, K. J. Tonight there is going to be a reception at the Computer Museum and buses are leaving from the Hines at 5:00, 5:30 and 6:00, and there's no video or audio taping of this, and there we've got that. Okay.

The way we're going to do this is John Derry will speak next and then all our other panelists will speak and then we'll have questions. So you need to sort of keep track of your questions.

John has a BFA in Painting and Drawing from the University of Nebraska at Omaha and a MFA in Painting from Cranbrook Academy of Art in Michigan. He has been involved in computer graphics since 1982. John has found exciting ways to combine traditional methods with computer graphics 
to create pieces unique to both worlds. He feels that the public has become so visually aware that the static image has to have more excitement in it to compete with the many moving images that people see each day. Derry enjoys each new project and approaches it as a creative challenge. He works in the areas of fine art and pre-press.

\section{John Derry \\ Time Arts}

Thank you, Rachel. When Rachel was just talking right now, it reminded me of a few years ago when I was myself was trying to get involved with computer graphics. I had attended a lecture and conference out on the West Coast and I remember I went to one of the panels and Carl Rosendahl of PDI was speaking at it. So after this thing was over, I kind of hung around outside and was waiting and I thought this will be my big chance, you know. I'll get my opportunity to get up to this guy and ask him some questions.

So when he came out and I saw him walking down the hall, I kind of ran up to him and I said - "Hi, Carl, I'm John Derry, and I'm interested in computer graphics and I'm an artist and I'll do anything. I'll sweep floors; I'll sweep floors." And it didn't work, but it reminded me that if you haven't - if you're here looking for that, obviously, there's a lot of different routes to try and sometimes it doesn't hurt to see if you can sweep floors somewhere, but you probably want to do more than that.

My own background is principally fine art. I have a bachelors and a masters degree in painting and drawing, and that's really where I came from. Several years ago I got the opportunity to work for a cable television station when they were evolving in the VIDEOTEX system where you could shop and bank through your cable television. That's kind of been superseded now by some of the systems like - what you can do through your computer.

It gave me the opportunity to really kind of play with imaging at a very primitive level, but I remember the first time I saw this image that I had created on the screen. It just forever changed me and made me decide I really wanted to get into it in a big way. So fortunate for me, I've kind of, in the last few years, got heavily into the area of connecting PC-based equipment or computer graphics equipment up to the high end electronic pre-press systems, and that actually - where is our slide? I'm not getting a slide here.

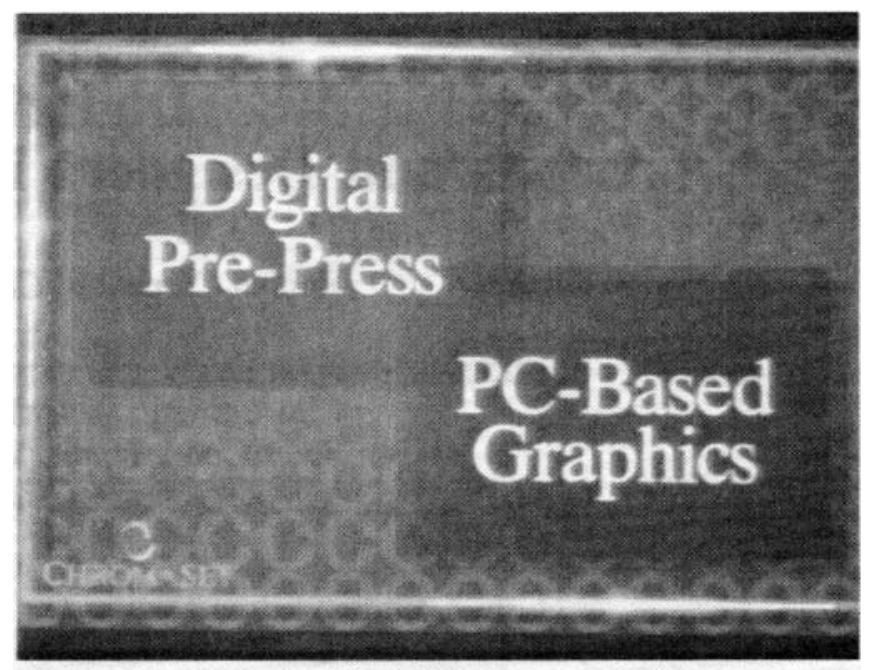

- DERRY - SLIDE 1 -

This slide kind of illustrates the first thing that I want to talk about, and you've kind of seen this same principle used to describe other areas that are starting to merge into one another. But a big thing that's happening is the power of personal computers. It is getting to a point where it's starting to, at its upper limits, match some of the lower capacities that are possible in the high end pre-press systems. And as a result, there is now what used to be two distinct areas starting to overlap, and if you'll notice the way the image is constructed, there is a tiny amount of overlap between digital pre-press and PC-based graphics right now. That area is going to continue to grow and probably, somewhere down the road, those two areas will always be synonymous. There will still be some separate issues that they'll probably deal with, but in a lot of ways these two areas are going to become very close together.

What that does is, it opens up a lot of opportunities for artists that are starting to pick up these digital tools and use them for the variety of things that we're starting to see them used for. One of the major things I think we're going to start seeing in the near future and already happening is, there are a number of gateways or paths that you can get digital information into a pre-press system.

The place I worked - Chromaset - it was a little bit brute force. We had to do it with whatever means possible and sometimes we had to do all sorts of interesting tricks to get the information into the format that the pre-press system understood. But once we were able to do that, it gave us a unique ability to create imagery and do things that you just can't do in some of the traditional media, and I have some examples that you'll see here in a minute.

So the first thing I think is important to note, is this overlap of these two technologies. That's where you're going to see a lot of action and I think that's going to create a lot of jobs or opportunities for artists in a print-oriented environment.

The second thing is that there's starting to be a wider diversity of the types of service output bureaus that are available to artists. It used to be you had to figure out how do I get this off the screen and into some format that's useful to somebody else? In a large degree service bureaus of different ilks are starting to address that issue and it gives the artist 
really a direct path to be able to get their imagery into things like a high end pre-press system.

So once again, the advent and the presence of these service bureaus is starting to give us more possibilities in how to take our imagery to the next step.

Finally, I think the third thing is I just had a conversation with a designer in Santa Rosa where I am now, and he was three years ago when I visited his office, he was totally non computer graphic. He was not foreseeably going to move to computer graphics in the near future. Thrce years go by. I go into his office last week. There's a Macintosh at every station and I said, "Gee, Glen, I remember when you weren't ever going to get any computers." He said, "Well, we just decided we had to get current and now that we have this tool it's just we can never go back." And one of the things that he brought up that I thought was kind of interesting. He was saying now that they have these digital tools in their office, their clientele actually view the designer a little bit different. All of a sudden there's this new respect for this designer that's using computers as a tool to design with. So from his end, he's seeing it not only as a tool that's actually valuable for streamlining his work, but the perception of the client now has changed because of the computerization of the design studio has actually sort of lifted them up a notch or something. It gives them a little more credibility.

What I'd like to do now is just go through some examples of the kind of thing that I've been involved with and hopefully it will give you a little bit of insight into exactly what we have done with this ability to go into pre-press.

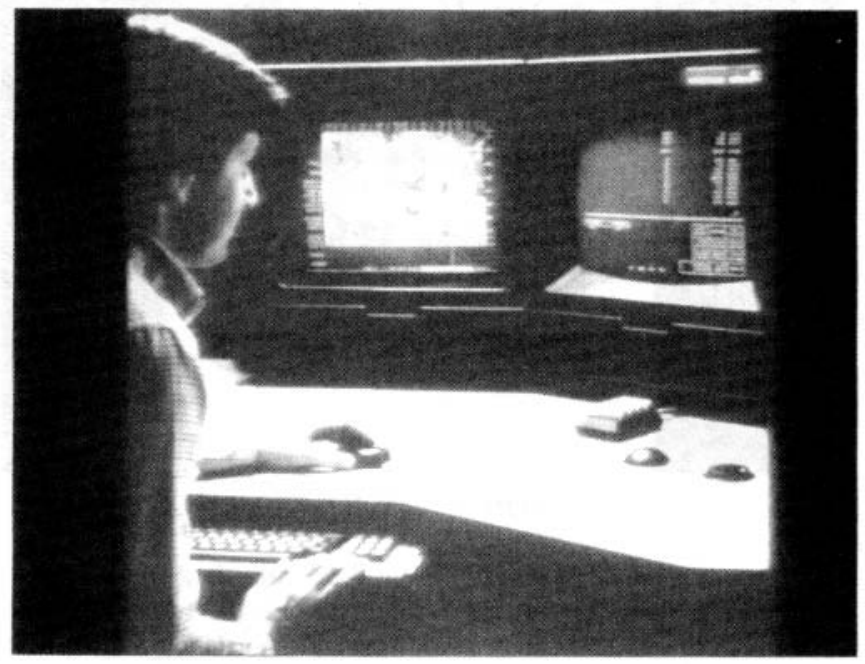

- DERRY - SLIDE 2 -

I think everybody has by now become aware of the high end pre-press systems like the SCITEX, HELL, CROSFIELD. These systems are designed specifically to manipulate high resolution imagery and keep track of it in terms of the cyan, magenta, yellow, black content of those images. And in that they do that, they really aren't creative workstations. They are production workstations that combine a number of tasks to one operator to kind of streamine the process.

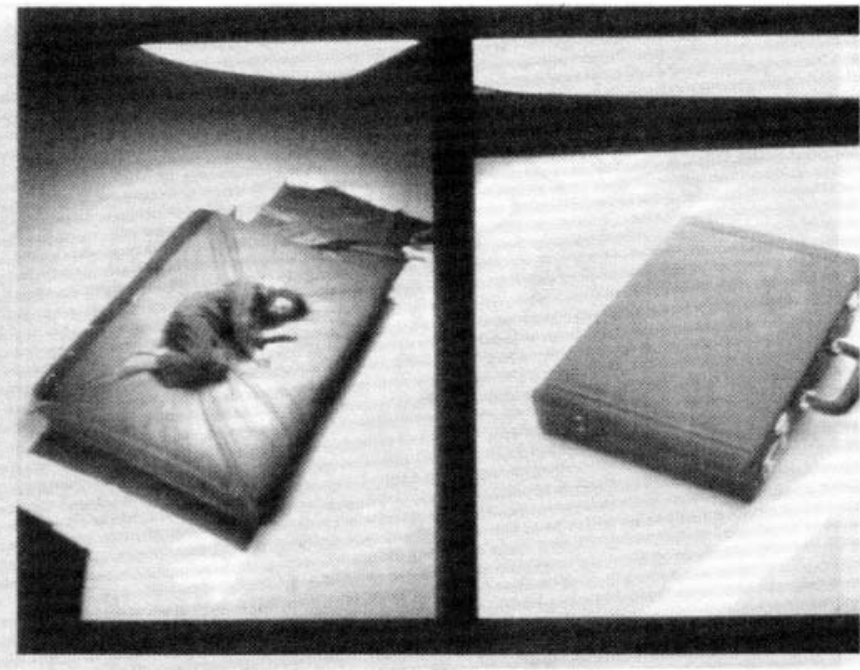

\section{- DERRY - SLIDE 3 -}

Here's a typical type of a job that would be done on the SCITEX. A couple photographs will be taken. Obviously, this one's done so that they know ahead of time what they're going to do.

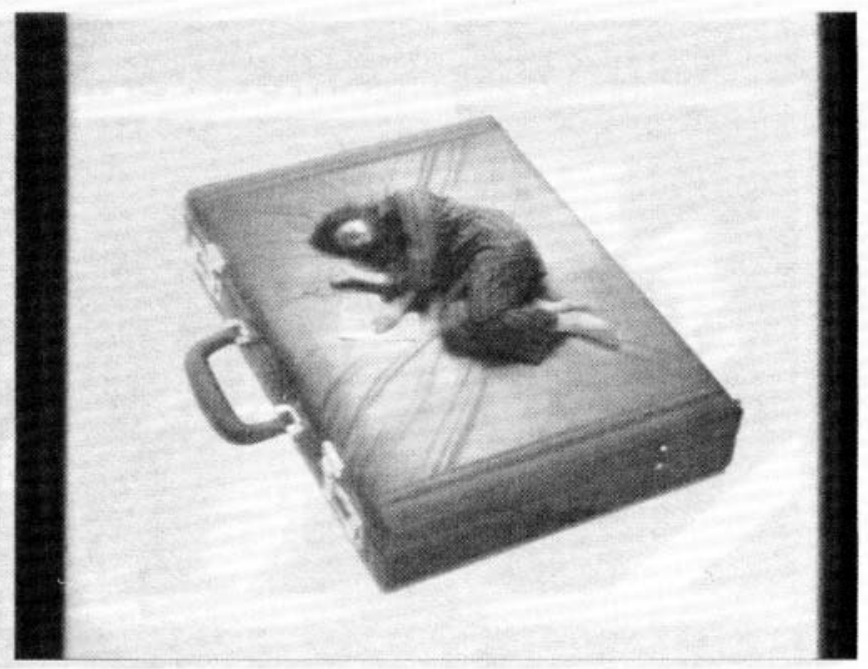

- DERRY - SLIDE 4 -

But the SCITEX will take the two images and composite them together so that you get an interesting photographic illusion that can communicate a message that you might not otherwise be able to do. 


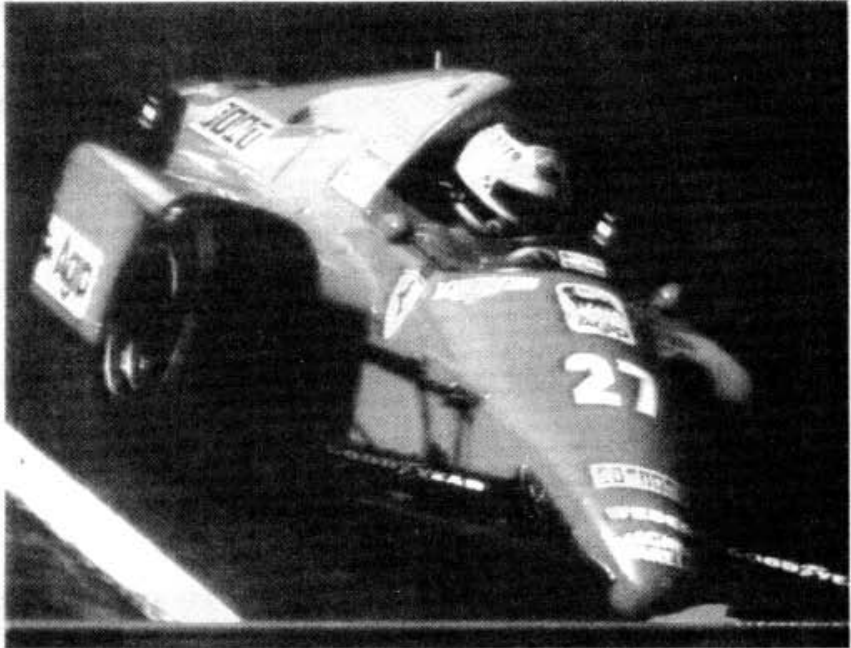

- DERRY - SLIDE 5 -

Here is a simple job of starting to use the PC to create special effects for existing photography. This was a job we did for Electronic Arts called Ferrari. What they wanted to do was actually enhance the sense of motion with this particular piece.

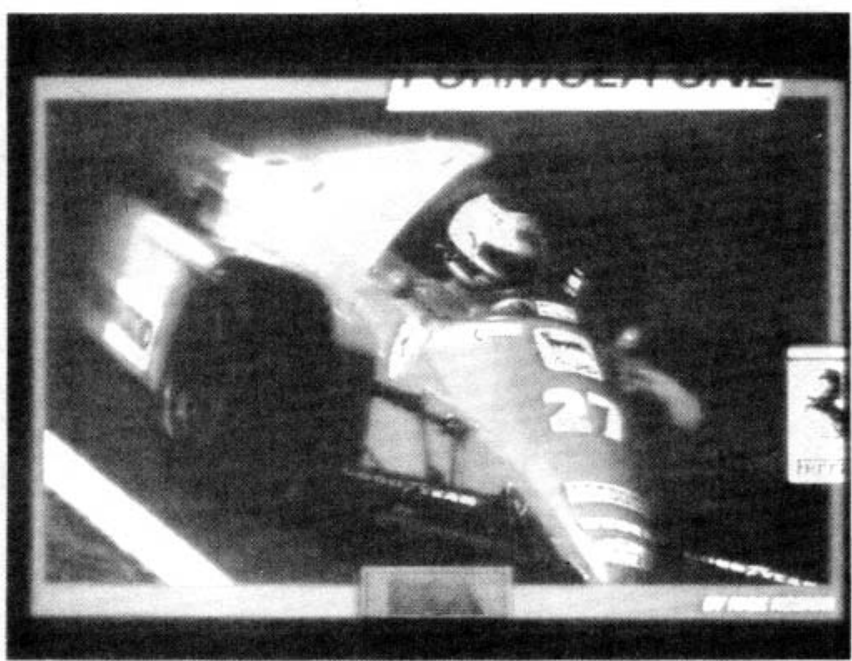

- DERRY - SLIDE 6-

So we actually took a low resolution version of the image into our paint system and added some blur. The blur was then separated from the rest of the image by the pre-press system and then the SCITEX operator booked the two images together and used their tools to feather the two pieces together into the finished piece.

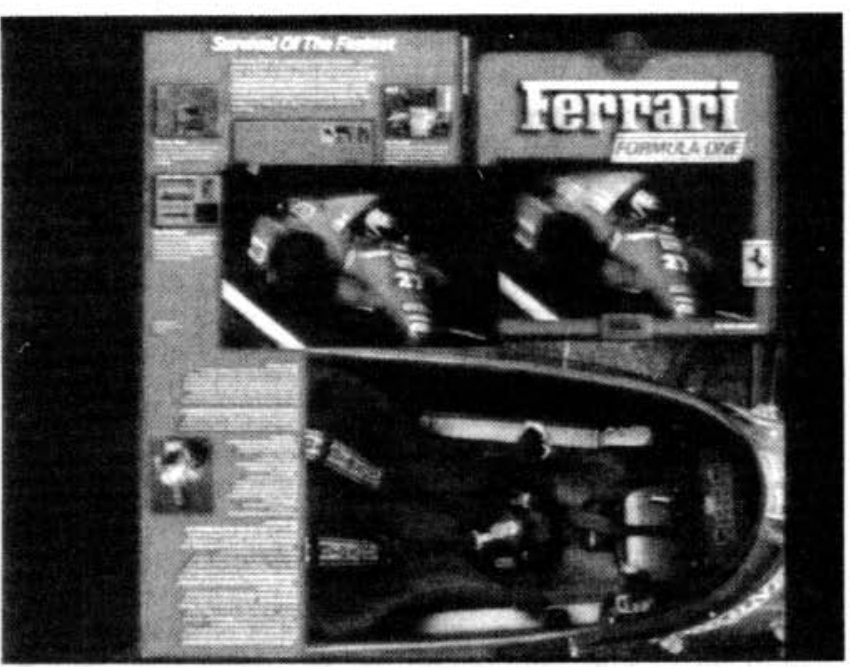

- DERRY - SLIDE 7 -

There is the final composite as it was set up for the packaging.

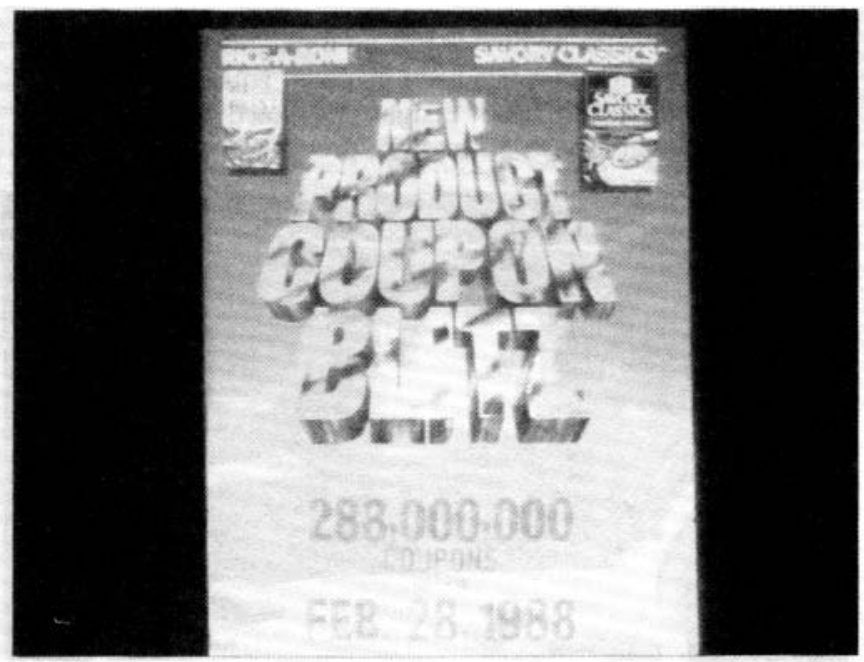

- DERRY - SLIDE 8 -

Here is another example. All of the air brushed work in the lettering was done with a digital paint system. So when a special effect like chrome or some sort of texture is needed, a lot of times the paint system can come to the aid of the prepress system to create those textures in a way that would not be possible otherwise. 


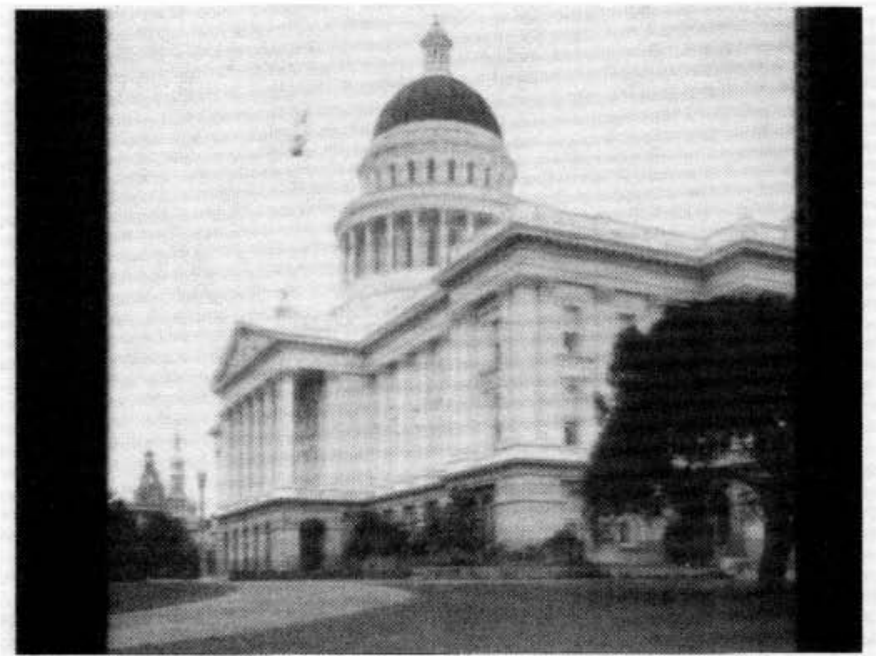

- DERRY - SLIDE $9-$

Here is another job that shows what you can do with the PC. This is a job we did for the Sacramento Bee, where they supplied us with the initial photograph of the state capitol, and what their idea was, they wanted to present kind of a Christmas card to the readership in Sacramento, and if you've ever been to Sacramento, you'll know it never snows there.

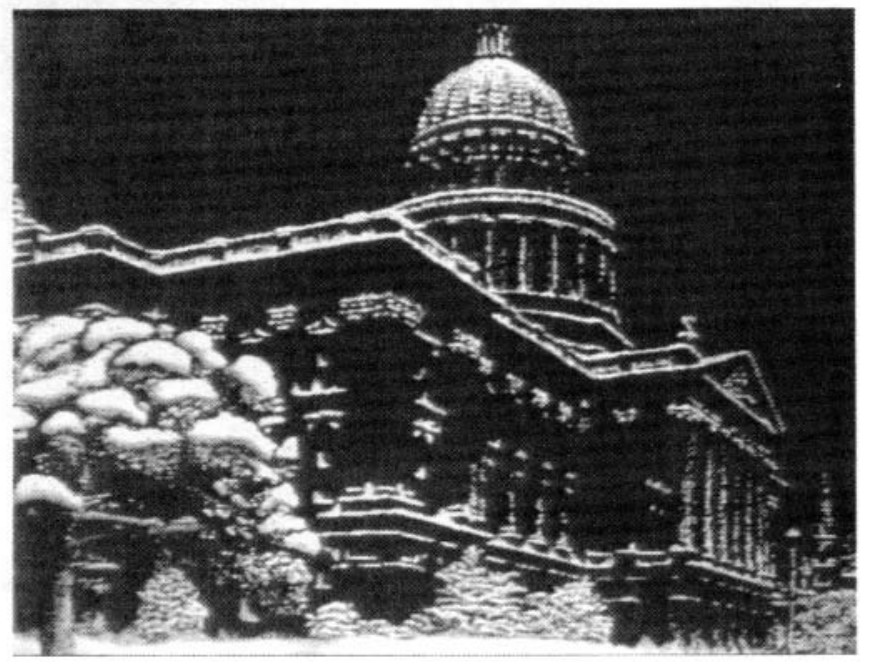

- DERRY - SLIDE $10-$

So what we did is, we created a snow using the low resolution image as a positioning guide, and once I had done that, I was able to remove the low resolution proxy image of the state capitol and end up with just this snow material.

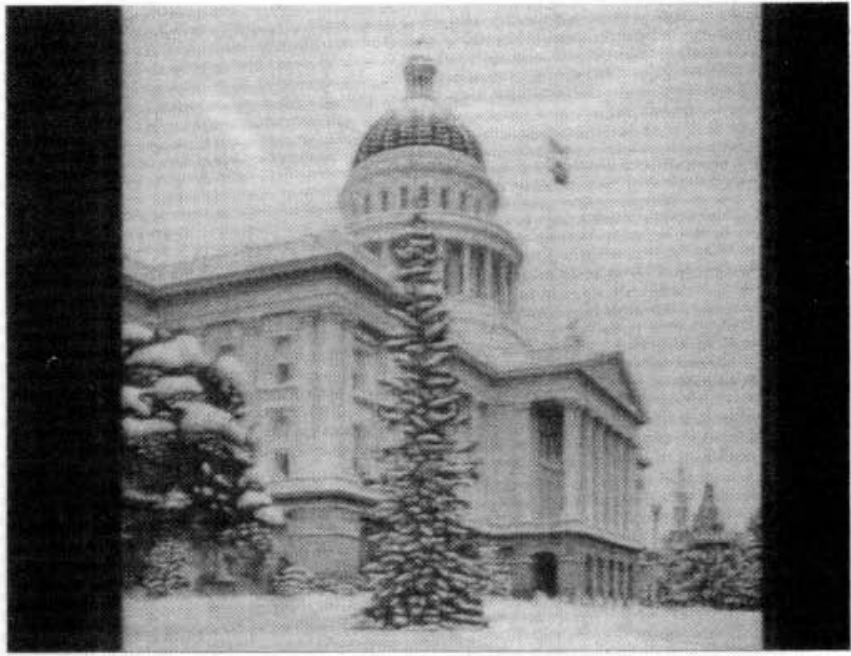

— DERRY - SLIDE 11 -

Then we matched that onto the image that we had in the SCITEX to combine them together to get a simulation of a snow scene.

I'm going to go through a project here that will quickly show you the evolutionary steps, and hopefully if you're already engaged in traditional design media, you'll see how this process is very dynamic and can change.

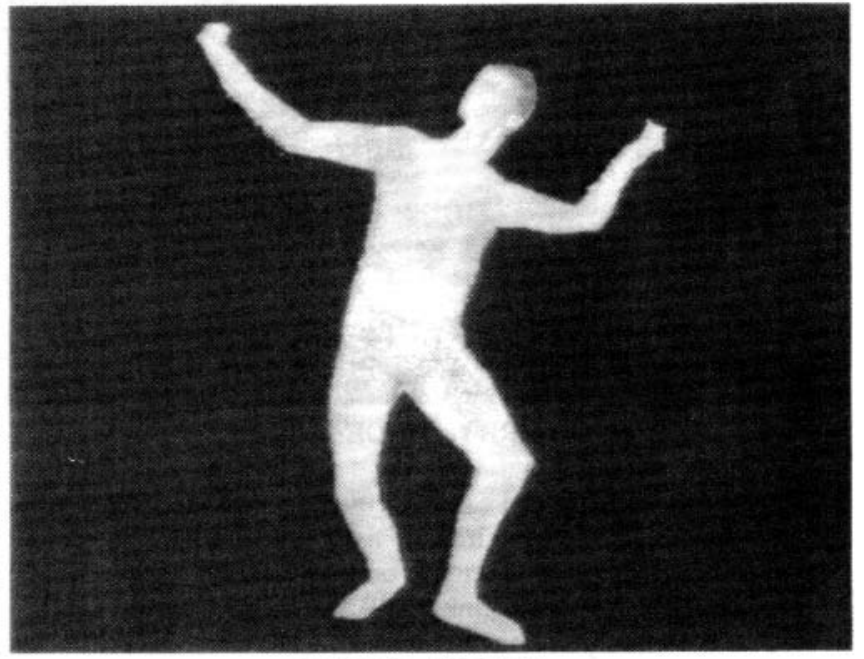

- DERRY - SLIDE 12 - 


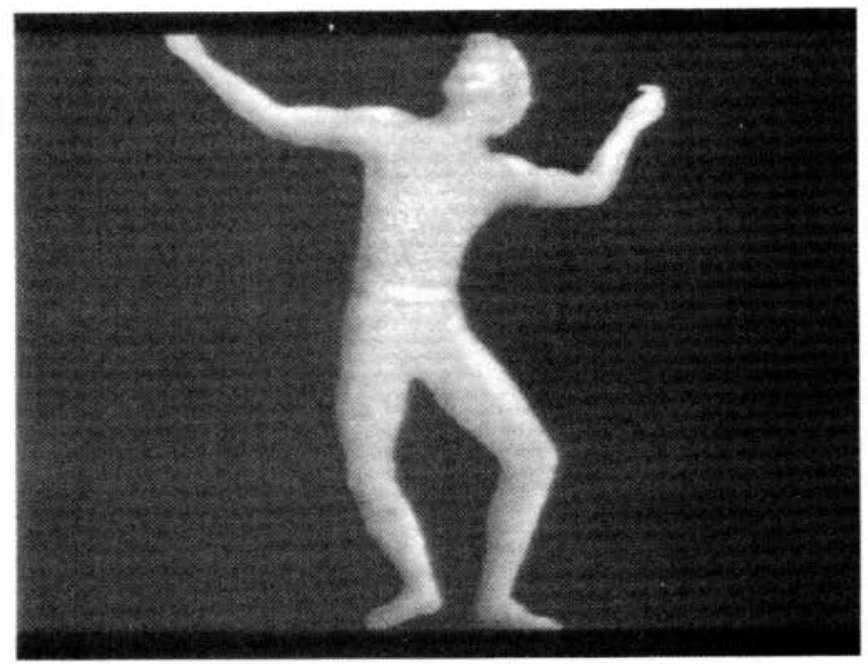

- DERRY - SLIDE 13 -

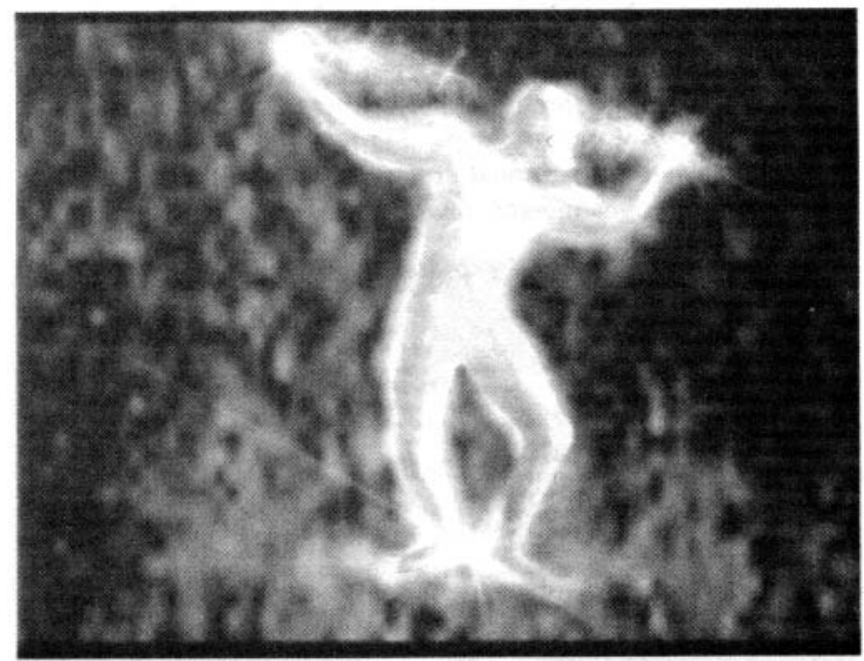

- DERRY - SLIDE $14-$

This was for a CD and cassette cover and the idea was to create a dancer that had the look of light emitting from it. I'm not going to necessarily comment on every one of these, but I'll go through them and I think you'll see how we slowly evolve to the final piece.

They started asking about things like modeling a little bit to give it a sculpted quality. We started talking about the background. Again, these are things that on the screen we're able to do in a very short amount of time. So what you're seeing here compressed into a short slide show, we probably went through in terms of time with the client at the system, a matter of maybe four or five hours they were able to see all these iterations.

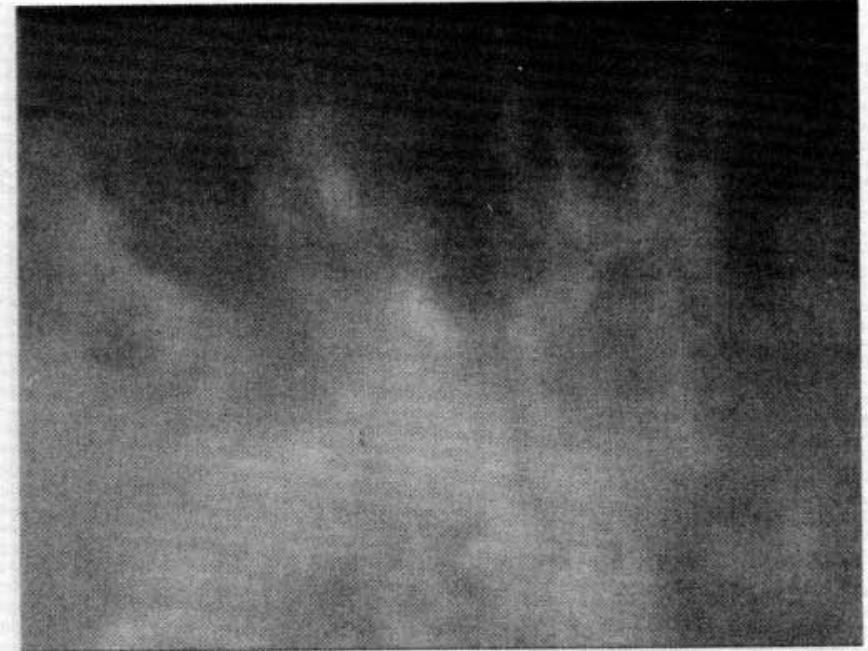

- DERRY - SLIDE 15 -

Later on we worked on the background. They brought in a photograph with some smoke behind it that they liked and I used that as a guide and went ahead and just painted basically an approximation of the kind of background they were asking for.

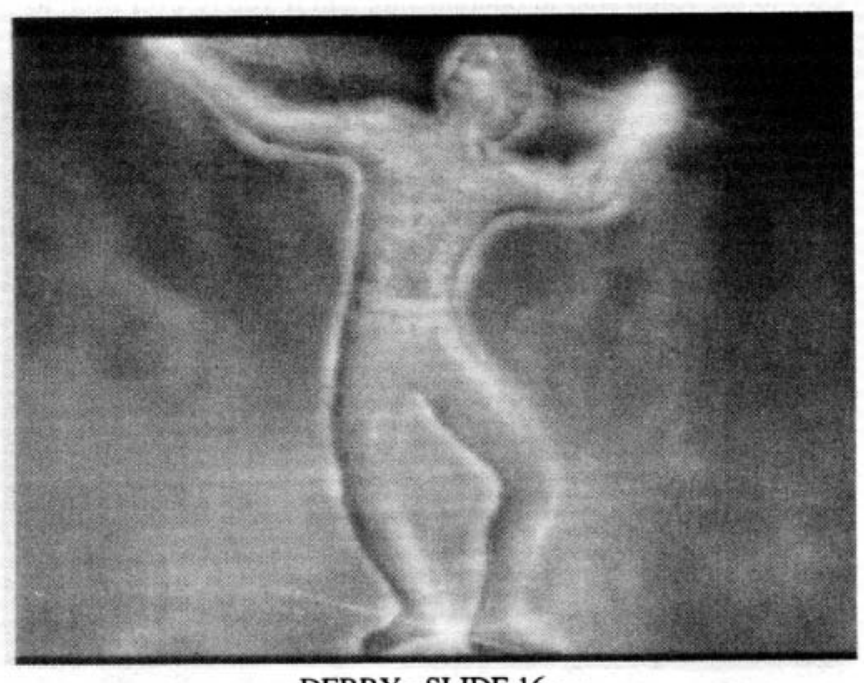

So now we've got the background we want; now we still need to work on the dancer some more. So we put the dancer on. They started talking about the quality of light as it might come off of the hands and then a slight glow around it. So we were able to add that at this stage, and again, this is all experimental. We're just testing our ideas. 


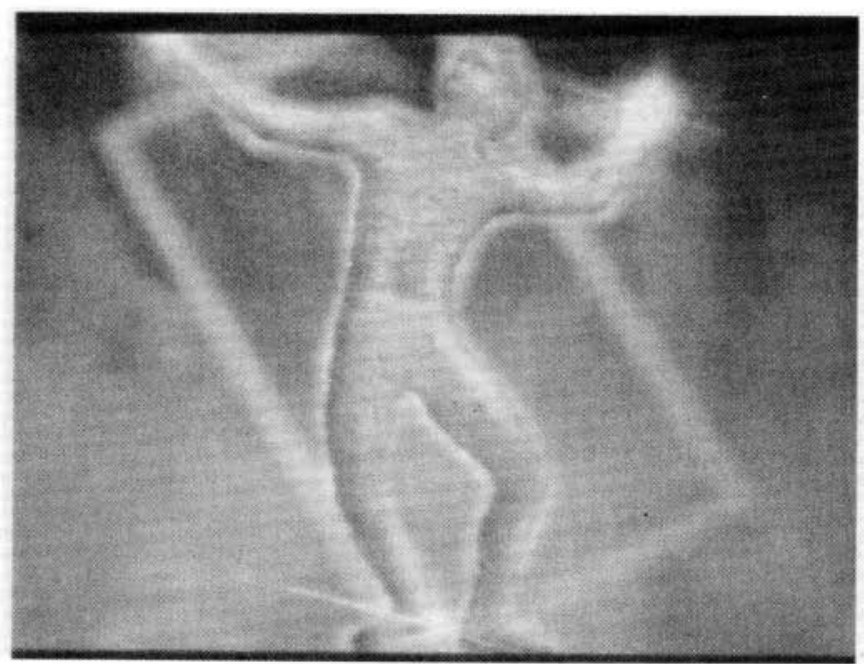

- DERRY - SLIDE $17-$

Another concept or element that had to be present was how do we frame this so that it fits within the structure of a cassette package and a square CD package. So at this point we're trying different ideas. His initial thought was to try some solt of rectangular shape. It looks a little awkward and you'll see later on we were able to get around that.

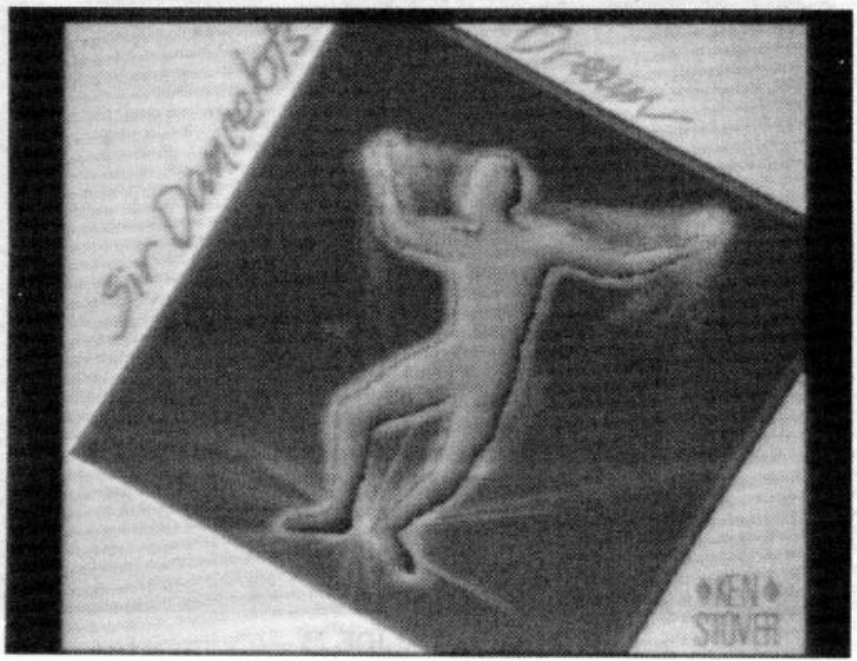

- DERRY - SLIDE 18 -

Here we are now. We're taking these elements and trying to see how they would look within an actual package environment. So we start to put things together that way.

Now we had a problem, in that we went all the way up to what you just saw and it turned out that the dancer itself was not - it just wasn't the right pose.

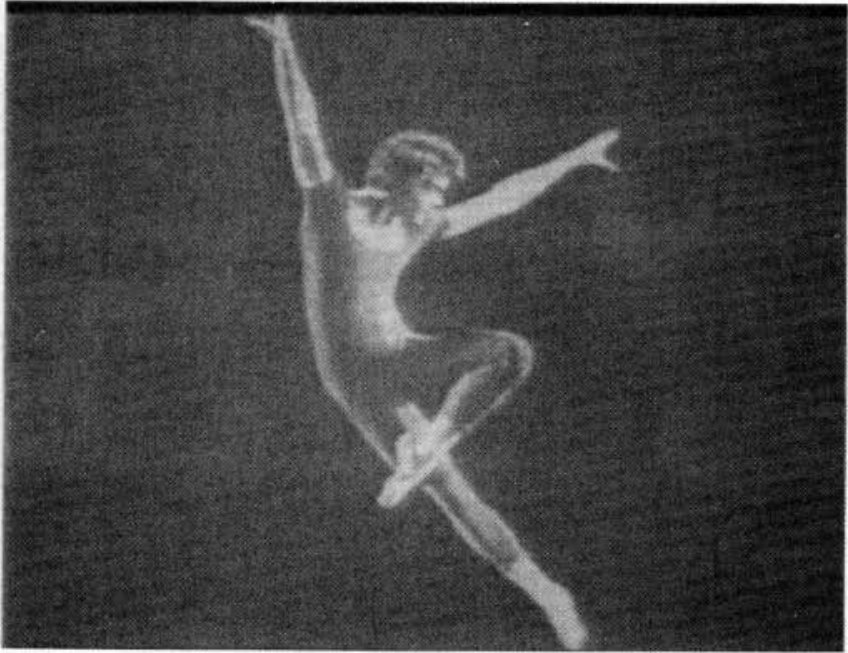

- DERRY - SLIDE 19

So they found another image of a dancer that they liked, and my first question I had about it was the actual silhouette of the face. I thought we might lose the chin in the type of technique we were using on it.

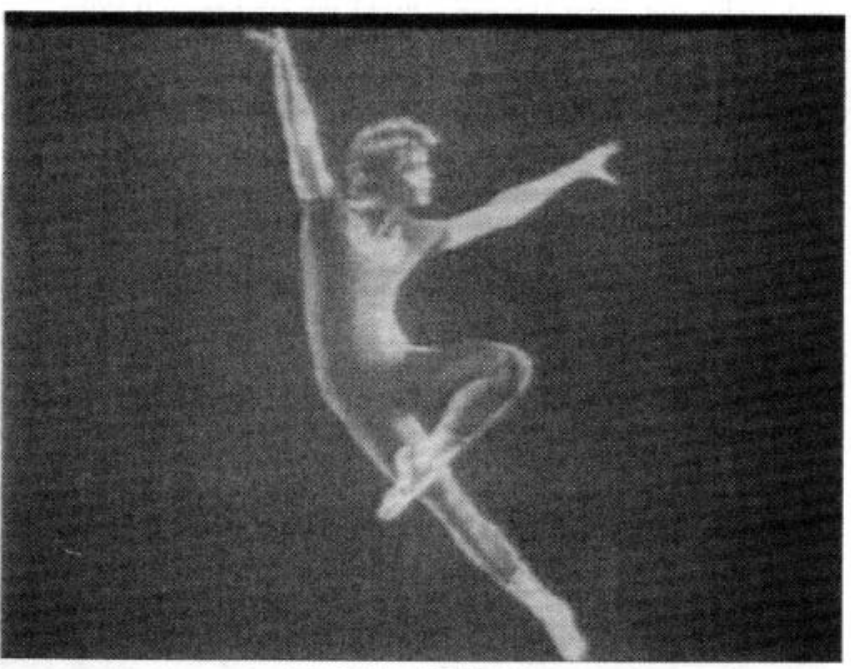

- DERRY - SLIDE $20-$

So I was able to, with the system, just quickly try a variation so we could see what it looked like. 


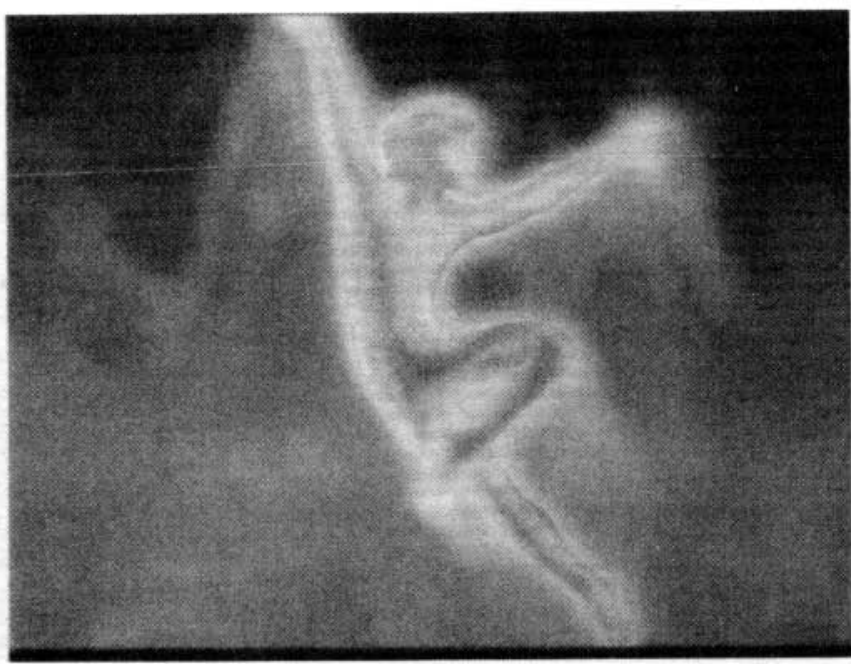

- DERRY - SLIDE 21 -

We actually tried this one out, but the funny thing about is, that for a dancer to jump in the way that that dancer jumped in that image, it would be physically impossible for them to probably have their head in that attitude. So it doesn't quite look right, and when you apply all of the stuff to it, it comes off looking like Tinkerbell or something, and that's not the effect we wanted. I mean, it looks like right now like you go zoom, zoom, left, right, up, down, and we realize well, we can't do that.

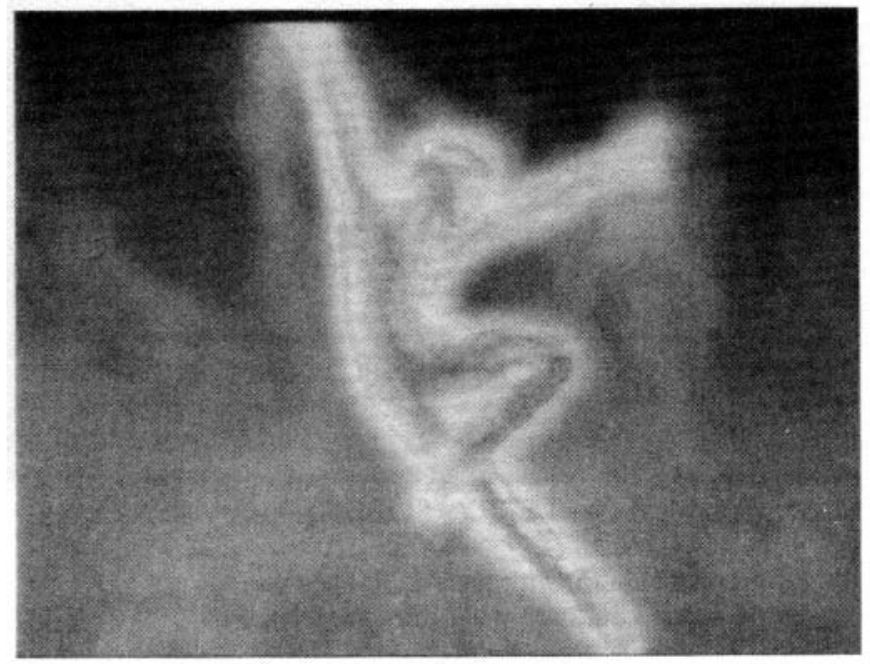

- DERRY - SLIDE $22-$

So I went back to the original one and we just tilted it down and by using a back lighting technique I was able to bring the chin to the foreground.

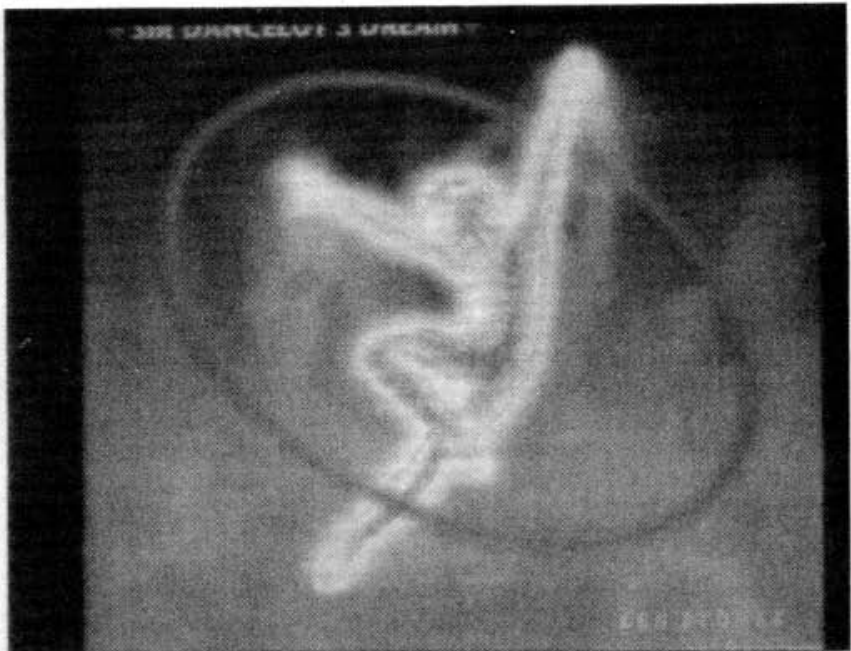

- DERRY - SLIDE $23-$

Now you're starting to see this is pretty close to the final artwork. From there we try a few comps. Here's where you can see we were able to get around that sort of awkward rectangular space and the arc or the parabola was a really nice way to frame him.

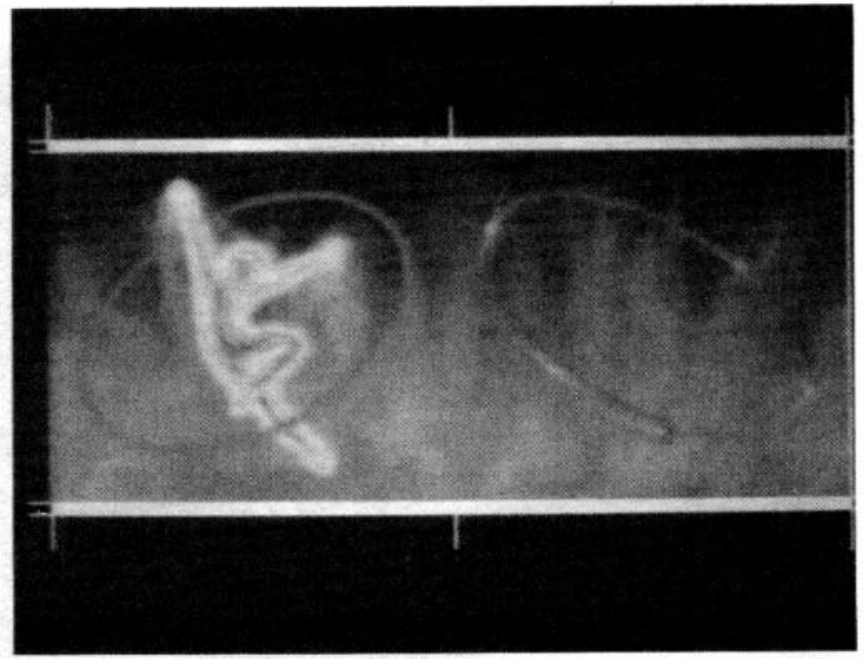

- DERRY - SLIDE $24-$

Here we are starting to figure out how, the way a $C D$ packaging works. There's a front and a back that fits in the flat. Since it's all being printed in four color, a lot of times the designer or the person responsible wants to use all that up. So we kind of came up with this idea of continuing the theme of the ellipse and just try a little different treatment on it. So that when the package opens up, that would be on the back, on the inside of the packaging. 


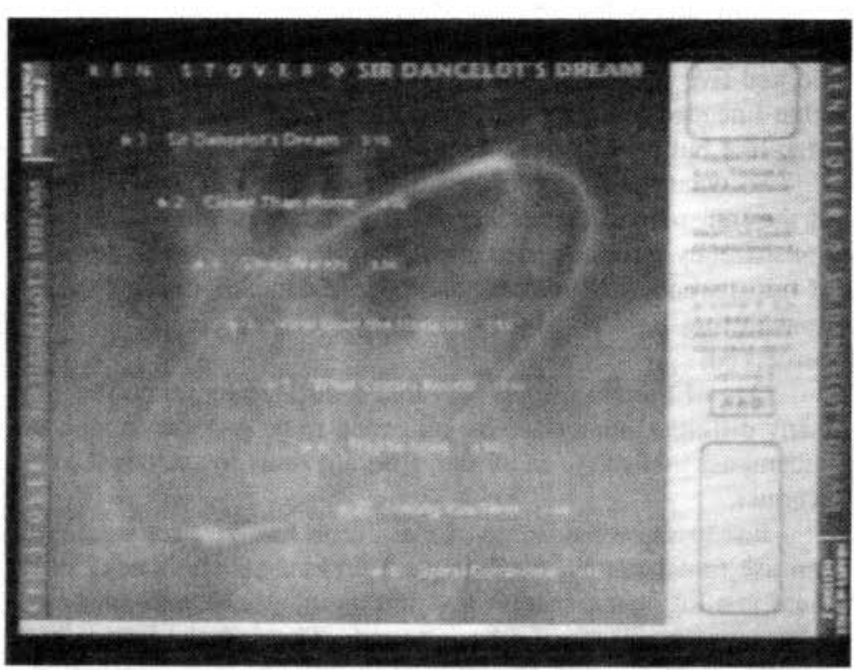

- DERRY - SLIDE 25 -

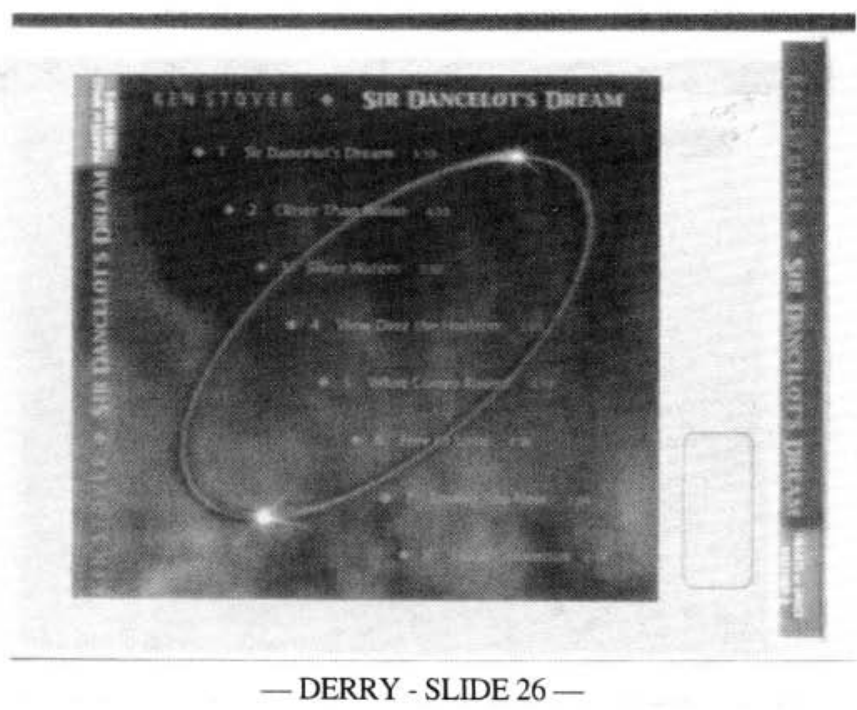

Here is the back side with the titling and everything on it, and once again, you can see we're continuing the theme of the ellipse throughout. And that kind of evolved during the process. He didn't walk in there saying I want to do an ellipse on all three panels. As he saw the first one, he realized gee, maybe we could continue that theme on. So some of this actually evolved because of the dynamic quality of the environment of designing with a computer graphics system.

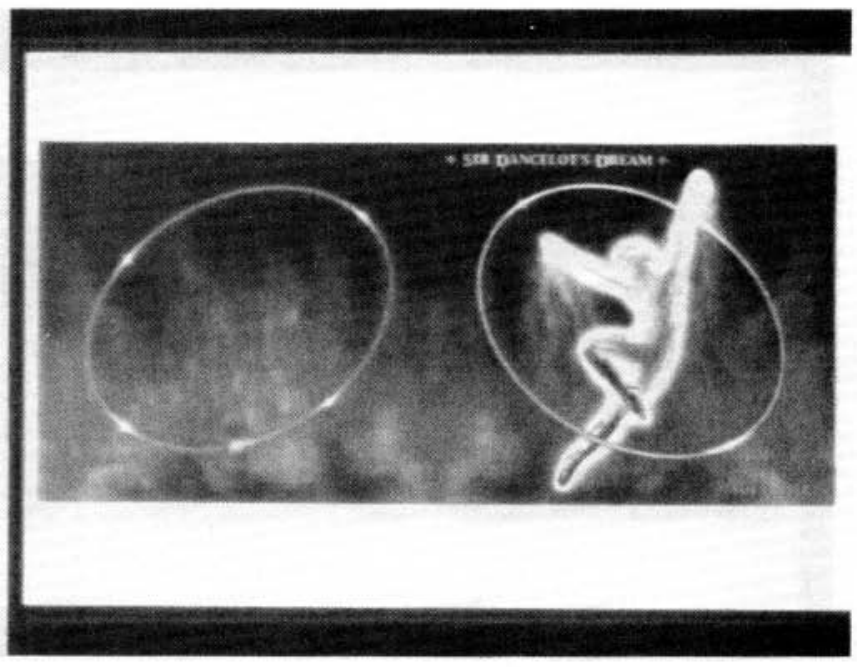

- DERRY - SLIDE 27 -

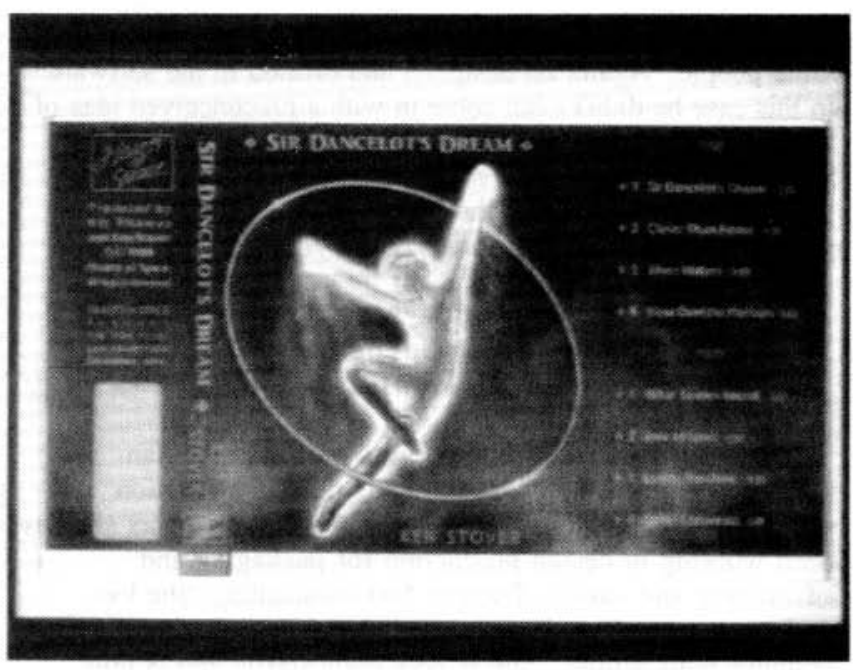

- DERRY - SLIDE 28 -

Now herc is the final actual finished covers. They got a litle dark in the translation to slide, but I think you can see that the ability to previsualize this on the system to final product carries across pretty nicely. Plus all of the artwork that is on the final work came from the system. So the file really did come off of the paint system. 


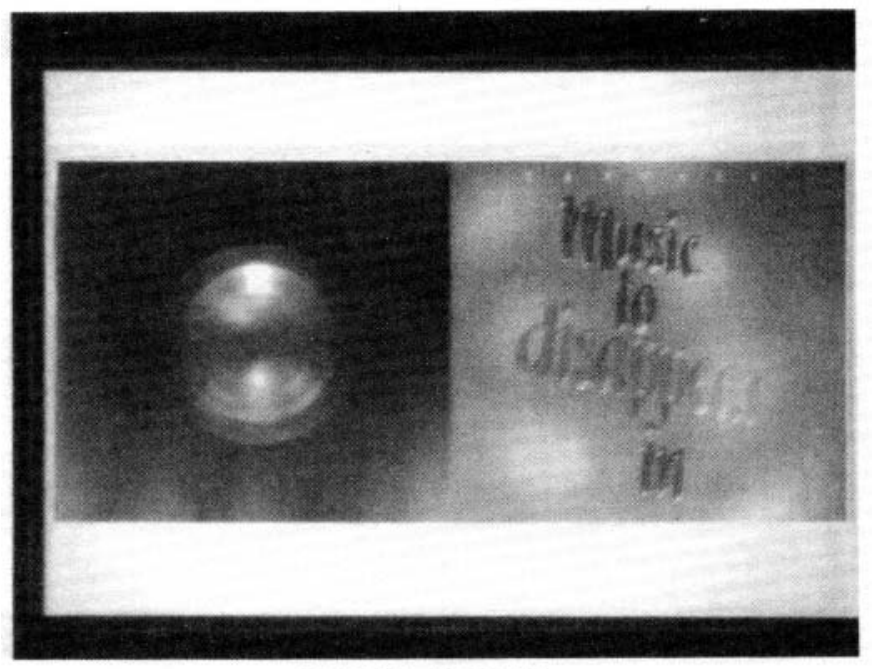

- DERRY - SLIDE 29 -

Here's another - this is a separate cover that we did same people. Again, all designed and created in the software. In this case he didn't even come in with a preconceived idea of what he wanted. We just sat down and started talking about ideas and you finally evolved to what you see here.

Well, that's basically the end of my presentation. So I guess I'll turn it over to Claire. Thank you.

\section{Moderator \\ Rachel Carpenter Cinematrix}

Thanks, John. Claire Barry was trained at the San Francisco Academy of Art in graphic design, animation systems and computer graphics. For the past six years she has been working in design production for packaging and advertising and various Fortune 500 companies. She has spoken at several conferences and she enjoy's sharing computer graphics with people. She is very enthusiastic and is now working with engineers on developing paint tools at SuperMac Technology. Claire.

\section{Claire Barry SuperMac Technology}

As Rachel said, I've been using computer graphics for quite a while, and at the beginning of this year I came to work with SuperMac Technology.

What I'm going to talk about is how I did work on interface design and I think it's kind of an important area for designers to consider. I think as computers become more a part of all of our lives, interface design may be a topic in school that you can major in, just like fashion design and graphic design. So I think it's really important for an artist to consider as well as programmers, because I do really believe that an interface should be designed. It shouldn't just happen.

When the Macintosh II was introduced, SuperMac Technology released the first color paint package, which was Pixel Paint, and this slide is an image of the original MacPaint interface, and in January what I was brought in to do was to define the tools for a new True Color paint program and to design the interface for the program.
Now this is the original MacPaint interface and with the increased capabilities and the technology, the interface which worked five years ago didn't work with the new tools today. So what I needed to do was design the interface which was still Mac-like but encompass the new True Color functionality.

So what I'm going to do is take you through the evolution of the transparency interface. The objective of the transparency interface is to allow the user to define the degree of transparency. Now transparency as defined is capable of transmitting light so objects or images can be clearly perceived.

One of the challenges was that transparency related to many different functions. So it needed to be general enough to encompass and relate to all the different tools in the new product.

Just to show you some of the effects that you get when you can use transparency, the reflection underneath the Kodak box, there is a lot of transparent text in this image, as well as some transparent images in the background. Through the lens is a transparent film. The background in this image is transparent and in this case the entire logo is transparent. So just so you get an idea of what transparency actually gives a user.

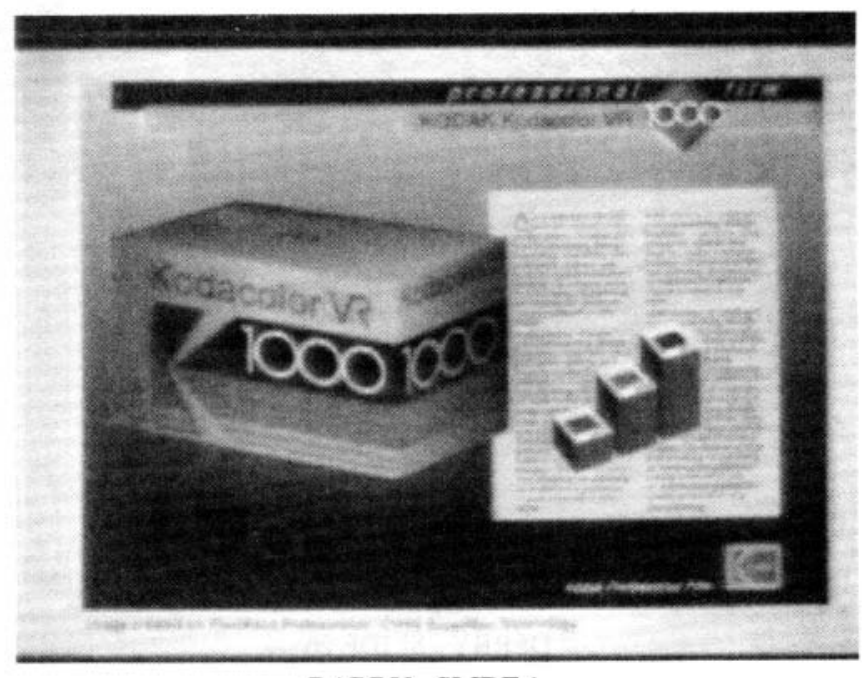

- BARRY - SLIDE 1 -

My first idea was to take the original color selector from Pixel Paint and expand it to allow the user to select transparency. This image is of the color selector, and as you can see in the blow-up, there are two overlapping squares. That's the foreground and the blend color. I thought by adjusting it a bit I could make the overlapping area indicate the area of transparency.

So what I did is integrated it into a dialogue box with a scroll bar underneath that allowed the user to adjust the degree of transparency, and as you can see, in the overlapping area, as I flip through, as the user would change the percentage, the color of the overlapping squares would change as well.

That was a pretty clean and effective solution I thought. But it did have a few problems I'm going to go through with you my thinking process on this.

The first problem was that it implied a link between the foreground and blend color, which suggested that the capabilities were limited, that it could only be used between those two colors. 
The second I felt was that it didn't really show how transparency affected multiple colors, and I thought that that was really important. In a True Color program you can use up to 16 million colors and this limited the potential.

The third problem was that it isn't really accessible quickly to the user. This would need to be accessed through a pull-down window or double clicking somewhere on screen, and even though that's a pretty effective approach, it is many seconds delay and I definitely didn't want the artist to compromise the degree of transparency because of any time limits.

So what I did was went on to my second idea which - it was very important to me to address how transparency looked over multiple colors. So I took an image; I quickly used the Apple logo because it had multiple colors. I also tried balloons and rainbows, just something with multiple colors, and again putting in the same type of format of the dialogue box with the scroll bar. The way this would work would be the user adjusted the scroll bar, the degree of transparency would change

Now this introduced a whole new set of problems. It's basically pretty confusing. It definitely isn't an interface objective. It wasn't really clear and we did try this out with beta sites - whether the foreground was becoming opaque or the background was becoming a transparent. So it wasn't clear what those numbers were relating to.

The next concept I tried was where the numbers would change as the degree of transparency within the numbers changed - all interactively in real time. Needless to say, the programmers found that quite amusing. We got a laugh out of that. So I was given two books. I was new to the Macintosh at the time. I had worked on the platform that didn't have trash cans in the corner, and it was my misconception I think, coming into Macintosh platform, that the Macintosh interface was cute and if you couldn't remember "erase ": :", you were a wimp. So I was doing things that I thought were cute. What I began to leam from these two books - besides from Inside Macintosh, the reality of computing speed - I began to understand the Macintosh philosophy from the interface guideline book.

So just to outline some of the basic interface objectives which relate to at least my challenge in designing the transparency interface, the interactive objectives accessibility. Accessibility is "See and Use" as opposed to "Remember and Find". As I mentioned, the trash can in the corner. "See and Use" is "I see the trash can, I drag the folder to the trash can". It's easy.

"Remember and Find", I have to remember, erase, remove, delete - whatever it is - and then find out how to do it.

WYSIWYG (pronounced Whizzy Whig). What you see is what you get. If the interface doesn't give you a preview of what you're going to get, then what's the point of having the interface. If it's not a realistic interpretation of what your next actions are going to be, then it's pretty useless.

Feedback. Data coming towards the uscr. Numbers, as in the transparency. You want numerical data, you want visual feedback. So that was something to keep in mind.

Also delight. I just basically like to enjoy everything I do and I thought that the user should enjoy using and adjusting transparency. So that's something I always kept in mind as well.

The visual objectives - and these are basic graphic design objectives. Communicate. Graphic design is to communicate information and if the interface is cute for cute sake, then it's not very effective if it's not giving back the information that the user needs.

Simplicity. Basic fact that less is usually more. Except our sales team doesn't think so. But more is more.

Clarity. Is it obvious that this is a transparency interface? If it's not, then it's not going to be used.

So what I did at this point after beginning to understand these objectives, was to figure out which were the minimum visual elements that I needed to communicate transparency. I was really adamant about wanting to use a spectrum of color. I thought that the transparency needed to be shown over a spectrum of color

The second element would be some kind of transparency indicator and then of course some kind of percentage controls to adjust the transparency.

So with those elements in mind, I am going to show you the building of what becomes a lot closer to the end transparency interface.

The scroll bar on the Macintosh is to adjust information. So I thought that that would be a good place to incorporate the spectrum of color right into the scroll bar and then I overlaid what was the transparency indicator. As you can see while I flip through these slides, that as the user scrolls the transparency indicator left and right, the level of transparency inside of the scroll bar becomes less or more transparent giving the user the information about the degree of transparency.

This is becoming almost completely transparent. Then I added percentages. Again, just the numerical feedback. Then we put it back in the window, and it's interesting. I came from consumer package design, and the way that we would treat a packaging problem was to first work on the package and then put it back into its environment, which would be usually a supermarket shelf and then analyze it amongst the environment to see if it worked. What happened in this case - even though I liked the concept and I knew I was really close - it overwhelmed the interface. The bright colors on the pallet were just overwhelming to the user.

The second problem which when we actually applied the interface was that the arrow, the pointer used to adjust the scroll bar was covering up the information that I wanted to give back to the user. So that wasn't very effective. What I did then was brought it back to a more typical looking scroll bar and now when the user clicked on the sctoll bar the spectrum would pop up, and in this way it was nice because I was actually able to make the spectrum taller and similar to what I just showed you. As you move the transparency indicator left and right, the color becomes more transparent. Then we put that back in the window. Again, even though we're getting even closer, there was one last problem and that was that it was confusing because you had then double windows and also the windowing or the scroll bar metaphor was typically to indicate enlargement of a document. So that was pretty easy to solve. We just changed the look of the scrolling device. And it actually worked out better because we were able to eliminate the arrows which we felt that the user was probably going to actually be clicking on the scroll bar and adjusting from there as opposed to using the arrows at the end. So we eliminated those and added this scroll bar, and then when they clicked on it, it would pop up again. One last nice thing that was added was that whatever your current color - for instance, if I'm using red, there's a good chance I'm going to make transparent red text afterwards or a red shape - that would be indicated in the transparency indicator, whatever the color - green, blue, yellow - 
whatever it is. So it gave back even more information to the user about what they were going to do next. That's it in use in our window. The product, which is actually shipping next week, is Pixel Paint Professional from SuperMac Technology, and that's about it. That's one example of the interface evolution. There are many like that in a lot of our functions. Thank you

\section{Moderator Rachel Carpenter Cinematrix}

Thank you, Claire. Peter Conn is up next, and he and his wife, Coco, began the company Homer and Associates 12 years ago, and in doing the business they've had to build hardware, get and cost jobs, hire production staff, get the jobs out on time, and all of those things, Peter is going to tell us all about it.

Also Peter did the great SIGGRAPH '88 hit, Flying Logos, and I think we get to see it. Do we get to see it, Peter? Yes.

\section{Peter Conn \\ Homer and Associates}

Actually, I'm going to start by rolling the video. A couple rules. No smoking and no flash photography, please, (joke to go with the slides)

This is a little countdown we just finished for the Mexican Lottery.

\section{— VIDEO TAPE BEING PLAYED —}

I just put these few animations on here just to show the use of a data base. Everyone after Flying Logos wanted globes, and we tried to talk them out of it, but they just - it didn't matter how many globes they saw, they wanted a globe. So we gave them globes.

This is a new one we just finished. This is an ink company; they make colored inks. International. You can turn the music up for this.

\section{— VIDEO TAPE BEING PLAYED -}

I'll tell you about that one later:

This is animation that was done for a Diet Coke commercial and I put it on here because it's a real interesting simple concept that gets really great response and as a matter of fact, everyone right now wants the same thing. They see this and they want the Diet Coke look. I mean, this was done - I mean, we didn't even go to 1 inch. This was like $3 / 4$ layoff. This was monitor screens for a commercial and it's kind of interesting because especially dealing with commercial people, they really like to see what they get before they get it, and I think the commercial is on after this. So you can see how these screens were used.

\section{- VIDEO TAPE BEING PLAYED -}

You can stop the tape there. Basically I thought - not really knowing what to talk about - I would kind of tell you my story and you can deduce anything you want from it, but this is kind of what happened to me and it's just one little story.

Twelve years ago we started this company - Homer and Associates - and for many years we did music videos, some industrials. We had a slide animation system we were working on and did a lot of live action, but we were really known for integrating special effects with live action; that was the big thing. And we started building our own computers during that time, and we built a customized 24-channel visual mixing console which allowed you to do animation effects using slides and a real time joystick, and kind of got us into computers. This was definitely in the early days and the big change that happened was that at one point we wanted to put in a one-bit frame buffer and we saw an ad in the Recycler which is like the place you buy your couches and refrigerators and stuff for an eight-bit frame buffer. So we bought that and a paint system. This was like in 1980. Actually, Paul Rather wrote it. He's in the audience here. And we had ourselves an in- house paint system. This was just when Quantel Paint Box was coming out And we developed a system where you could take slides and using a motion control camera, you can move across them, digitize them, and do a lot of effects using color levels and color map cycling and it was all custom software, and it worked great. It had a real funky look to it, and 3D was just like a dream at that point. We weren't even thinking about it.

I guess it was in 1983 I did a music video for Steve Miller called Bongo Bongo and there was a machine that had just come out then, the FGS 4000, which was the first accessible 3D machine. They have them in video facilities. And basically I took a few shapes that people were doing logos with, some tetrahydra and stuck them together and made a character and did some primitive character animation, integrating with live action. But it was great. I thought this is really neat stuff and I've got to do this.

So I went to Bosch School and learned how to operate the machine and the next few years I would operate around town. There were a couple of them. And I learned 3D by doing this. The Bosch is a really awkward machine, but it really made a good learning tool because everything after that was so much easier to use.

Then actually getting into 3-D in-house was really almost another accident. It was 1986 in SIGGRAPH and I kind of came around the corner of this aisle and I saw this couple of guys with this system there, and they had this chrome donut with this chrome ball going through it, doing an environment map of this fractal landscape. I went, "Woa - that does that on a PC?" That's when we bought the first digital art system, and they were just starting it then. But I wasn't really looking to buy hardware because this was around the time where all the big computer graphics companies were going under and I wasn't planning to get into it. But at that level, if that system did that kind of animation, I thought I could do something - and especially since the Bosch was always a big problem because it couldn't do metallics and that's what everyone wanted reflections and everything.

So we got the first system and basically it just kind of built up from there. I had an advantage because in 12 years of doing work I had a lot of contact, so it was a lot easier to build up a reel from almost nothing. Most of the Flying Logos animations were done during the first year, year and a half. And we built up after about a year, added a full-time technical director, Michael Cory, and just started getting more jobs and developing our techniques.

Since then we've added several other systems. We added two Digital Arts. Then just recently we added an IRIS with Wavefront to do animation, and now we have a transputer based renderer running the Digital Arts RenderMan code, and that's actually a brand new thing for us. But it's a system that we've 
developed that works for us, and hopefully it does. We're all putting it together right now. And everything is ethernetted together and we're able to turn out quite a bit of animation on what a lot of people would call kind of small machines.

A couple of notes here. Certainly one problem I always had selling animation was the idea that we were working on PCs and competing against companies that had much fancier hardware and the way I came up with the basic ways to get around that. When they asked what kind of hardware you had, you always kind of said something like 32-bit workstation. You just basically - it really worked quite well. I totally avoided the issue of hardware.

A lot of people, I would never even show them the hardware, and I learned actually from years before when we had built this line animation system. We had put it in this giant oak console and it had like 3,000 LEDs on it and I thought this is really going to impress them, and it didn't matter, because you find out that clients really don't know anything about hardware and really aren't impressed by it. If you don't show it to them, it's just as well. And if you du, they don't know what they're looking at anyway. So you can tell them anything.

Clients. Usually the problem is they don't really know anything about 3D animation. So you have to kind of hold their hand. We use -- I don't have an example of it - but we have a 3D flow chart that I developed that kind of shows all the steps of doing animation - the storyboard, the ink coding, the Wireframe, the test lay-offs, the rendering. And it's actually a sign-off sheet. Now I sit down with them and I go, "These are all the steps." It actually makes them more comfortable because they think they understand.

Let's see. Costing jobs. We're supposed to talk about that. I don't know. It's a black science, as far as I can tell. I mean, certainly when you're making animation, there is labor, but it's not - I mean, you're making pixels. So it's a little different. You have creative fees, you have amortization of the equipment you've got to figure, and also you've got to figure what - if you take one job, what are you going to pass up because you only have so much capability.

Basically the way I have approached it; it's worked for me. You can do what you want. But we started small and we built and then as we had some minor successes we added more equipment and more staff and we're still just taking it easy. I mean, people have done other approaches where they go out and buy the fanciest most equipment you can, and certainly there is a trade-off there. You have to always figure on efficiency because in some ways hardware is cheap. If your hardware is going to hold you back, it can cost you a lot more in the long run.

Jobs and opportunities. I always see people - basically we're looking for people who have significant 3D capability. Both of the full-time people that work for me now worked on large systems and they brought that experience to our place. $3 \mathrm{D}$ is something certain people are better at than others and even when you're good, you need a lot of experience, a lot of time, a lot of production problems because you just - in every system you learn, it's very easy to learn another system after that. So it doesn't matter if you know Digital Arts or you know Wavefront - you can learn it if you've known other systems. But it's hard getting started because you don't get access to the equipment and so on. But we're always looking for new people to use.

I don't know. That was basically all the notes I had. It's a real exciting business. You don't get a lot of sleep. I usually play cleanup man, which means I don't do the animations, but when it gets down to the end and the deadline, you know, I'm dealing with the client. I go in and jump on there and help get things composited and laid off to video, which is always the last step. And it's pretty exciting and we expect to do - right now we're doing mainly commercials. We kind of went through our flying logo stage and now we're doing commercials. We'd actually like to do music videos again - kind of come full circle around there - because I think as we get rendering up to a place where we can put through a decent amount of animation and we start developing character animation a little bit more, I think there's a lot of things you can do in longer form pieces.

That's it. Okay.

\section{Moderator \\ Rachel Carpenter Cinematrix}

Last but not least - Vibeke Sorensen. Her background is primarily in architecture and art. Her range of experience includes producing computer animation and synthetic music, performance art, 3D stereoscopic imagery, teaching computer animation, and working with scientists. She has shown her work widely and has frequently collaborated with other artists. She's currently teaching at Cal Arts and consulting with San Diego Supercomputer Center. She's also got a piece in the art show, which I hope she'll tell us about.

\section{Vibeke Sorensen California Institute of the Arts}

Could I start with slides, please? I've done some design work in computer graphics, and among other things, various Christmas cards, including these two pictures for Rolland Synthesizers two years in a row. And also I've worked on a couple of Omnimax films. This one is the Magic Egg, which I believe has been or is being shown in context with this Conference. And a film called The Seasons, in which I modeled two models of the solar system - the Copernican and then the Ptolemaic, and by the way, in doing that I rediscovered the solar system myself. There are a lot of issues relating to that, but I don't really think I have time in the 10 minutes to talk about that.

Recently I worked at the Jet Propulsion Lab in Pasadena on a Mars Rover animation project in which I created a model of a robot arm prospecting on Mars, and I'd just like to show you a little of that. It's about 20 seconds. Can we go to the tape, please?

\section{- VIDEO TAPE BEING PLAYED -}

Okay, that's it; please stop the tape. Please stop the tape.

Primarily though I teach for a living, and this is by choice. This is the Dean of the School of Film and Video, Ed Emshwiller, working in what was one of our first set-ups in the lab. 


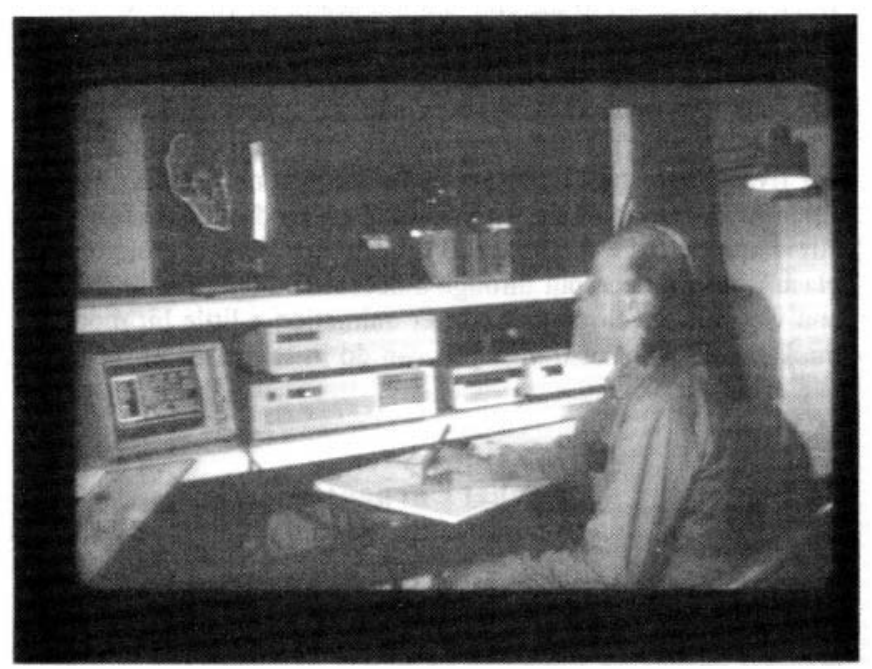

- SORENSEN - SLIDE 1 -

Ed Emshwiller in the Computer Animation Lab (C) 1985 Vibeke Sorensen, reprinted with permission

Teaching has been rewarding to me in many ways because in my value system, there are other rewards in life besides money - though money is important. And education comes closest to my ideals and my personal research work.

My personal work has in the past focused mainly on video as a medium for personal expression through moving images - especially abstract animation, which I consider to be a form of visual music. I went to computers for more control over the image. When I lost the realtime performance element of music at the beginning, hence, this picture, in which I'm trying to capture movement in a single image. My concern with the human articulation of time through gesture. I'm also trying to infuse new ideas into the popular form. Taking the music video format, for instance, in my piece called Solstice, and bringing historical and political concerns into it. In this case the transition from Pagan society to a Christian one.

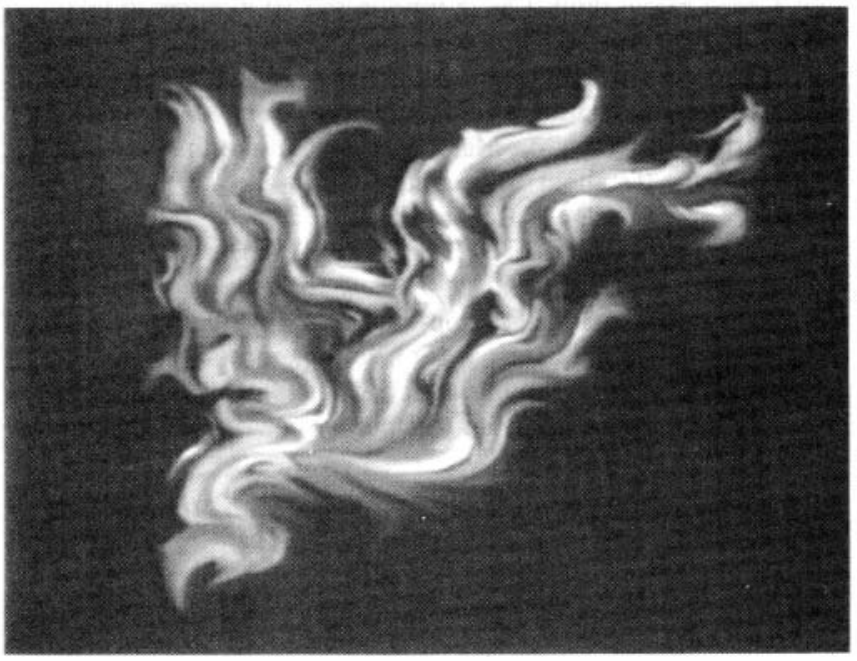

- SORENSEN - SLIDE 2 --

Cool Fire

(C) 1983 Vibeke Sorensen, reprinted with permission
You may be familiar with some of my other images, which are stereoscopic. This one's Fish and Chips, which explores the relationship between language and technology. The visual pun - the manifestation of this interest.

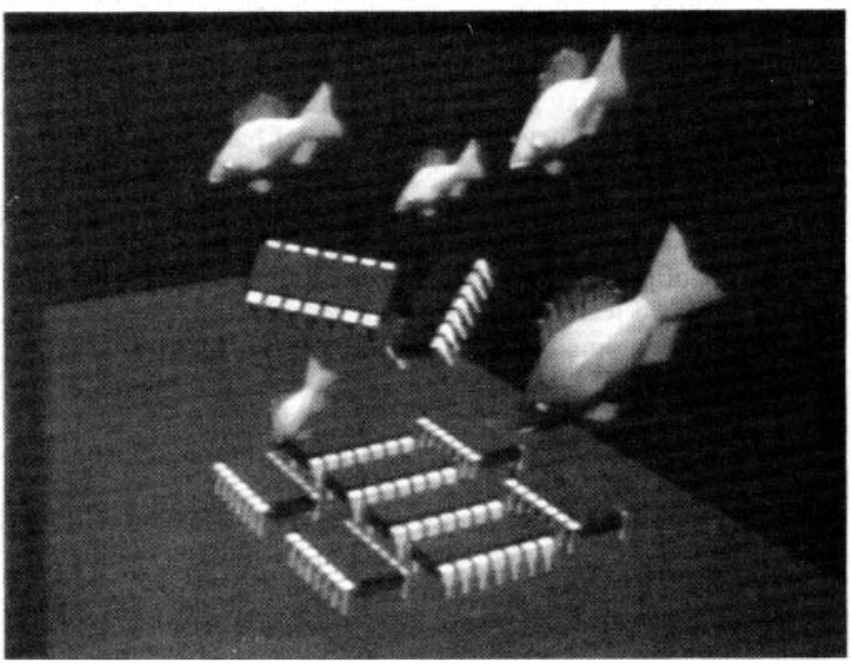

- SORENSEN - SLIDE 3 -

Fish and Chips

(C) 1985 Vibeke Sorensen, reprinted with permission

This is called Microfishe

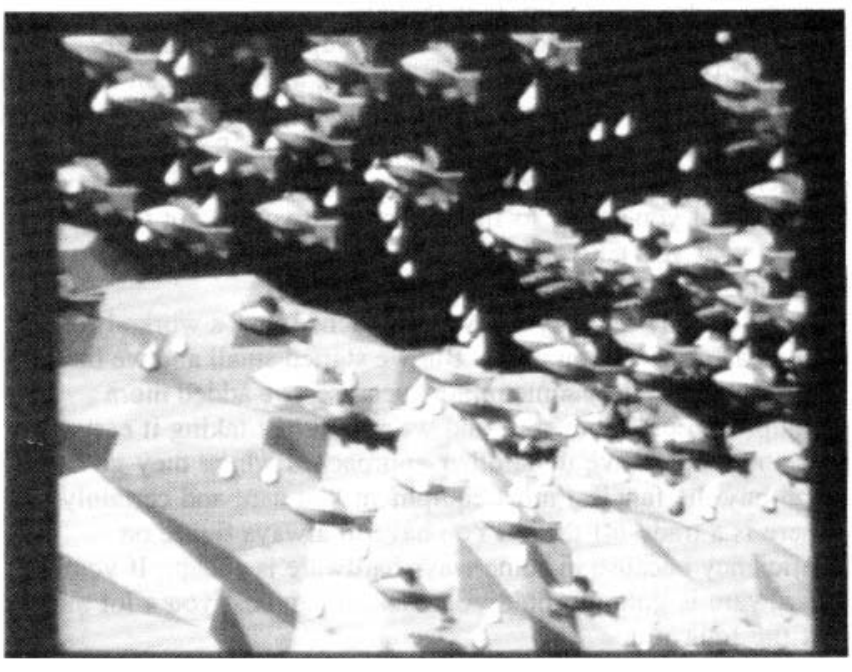

- SORENSEN - SLIDE 4 -

Microfishe

(C) 1985 Vibeke Sorensen, reprinted with permission

Parroty Bits. This is one of a series which I call, $I t$ 's Not a Bug; It's a Creature from "It's Not a Bug; It's a Feature". And I even tried to learn how to build an electronic sculpture. I felt that it was important to democratize technical knowledge and include it in our tool kit, if you will, for creative expression in the fine arts. This is called the Three Ring Circuit. Then I have my current work on the IRIS Wavefront system which involves a reflection study series. That's what it's called - The Reflection Study Series. 


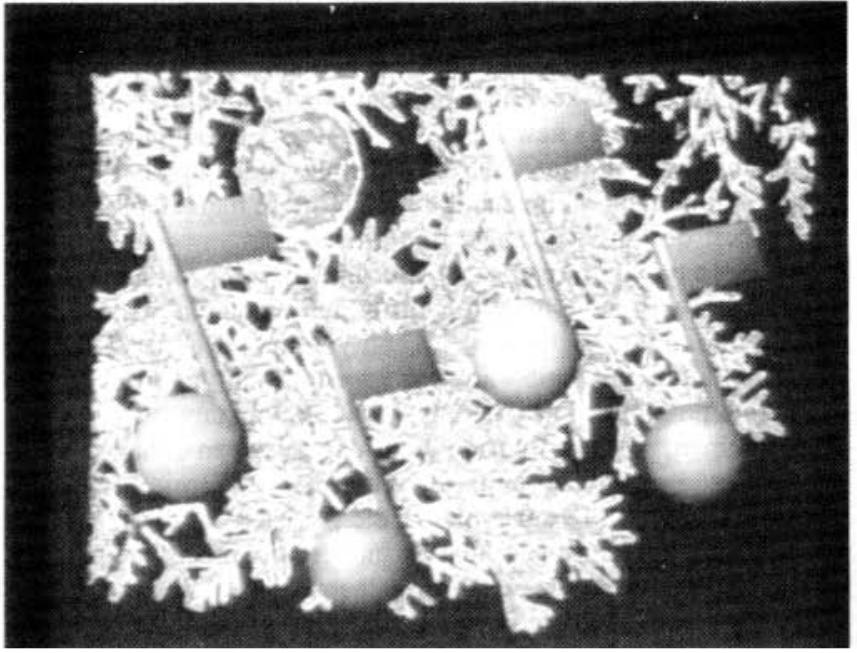

- SORENSEN - SLIDE 5 -

Christmas Card

(C) 1986 Vibeke Sorensen, reprinted with permission

in which I am exploring language, visual perception and images. These pieces are all stereoscopic and explore various parameters of simulated stereoscopic perception. I can vary independently the interaxial separation, scales of objects, including reflection maps and how the reflections behave.

My current video work in computer animation considers computer animation as voices in a musical ensemble abstract, as in music, but integrated into the live performance of music, and installations and galleries such as here in the SIGGRAPH Art Show, where animation art is in a more interactive and live or intimate context. Freeing it from the proscenium or theatrical forum. As Rachel said, you can see it upstairs in the Hines.

I'll just run through some of these.

Q. Vibeke, is this a large matrix?

SORENSEN: Right. This is a 9-monitor installation and this is just one frame from a single monitor, but it's shown what's that? Okay, and I'm just quickly rumning through some of these pictures.

In here, this last picture, you can see it in pelformance in Nice, France, in 1988 with the Percussions of Strasbourg performing live.

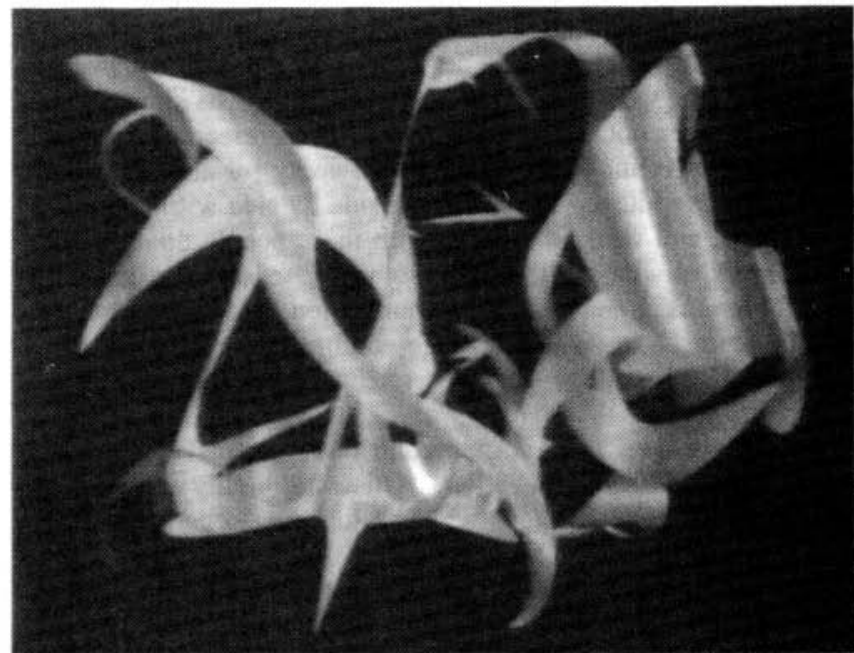

-..SORENSEN - SLIDE 6 -

Reflection Study No. 7

(C) 1988 Vibeke Sorensen, reprinted with permission

That's the end of my slides. Now I'd like to go on to the next half of my talk, which is a bit more philosophical. Pioneering interactions between artists and various branches of the wider marketplace I call industry have brought forth new opportunities and fruit benefitting both groups in tangible ways as we have heard from our panelists here. The synergy and productivity is generally very hopeful, and often inspiring for a new generation of artists who are seeking to align their creative intelligence with a rapidly changing high tech society.

These prototypes as role models include members of this audience and panel, and companies interested in prototyping future products. New user interfaces and hypermedia, such as and companics such as Apple Computer and Pacific Data Images, the National Center for Supercomputing Applications and the San Diego Supercomputer Center, who support their artists doing their own work, who support these people doing research, art being visual research, as a formal part of their employment.

Despite these admirable examples, the situation is still problematic. I feel that fine artists and in the marketplace are still basically incompatible because their value systems are so different. Where success in the marketplace is judged ultimately by financial success, success in the fine art world is defined by quality and innovation.

The marketplace can sometimes be unsupportive and uninformed - mistreating artists while simultaneously exploiting them. Artists should keep standards high, demand respect, and know that they hold a central knowledge for the development of the computer graphics visualization field. Artists should be treated as equals since computer graphics is an interdisciplinary field combining computer science and graphic art. Being part of a visual cultural, artists should be conscious and proud of their role, aware of their importance, and demand and receive the respect and compensation for their contribution to the field.

While artists can be used as illustrators and designers, a sometimes more profound and appropriate use of the artist in computer graphics is that of researcher. Artists are windows to the future. They are visionaries who pioneer new uses of 
technology, and in many ways though secondary to the goal of art making for art sake, Art is greater than or equal to applications. I am defining art making as a desire to transform or reflect the world as a visionary sees it. Artists should think of themselves not only as designers, but as researchers and pioneer's in technology. They should apply for and receive positions in industry and academia side by sicle with computer scientists, and work in tandem with these people doing their own work as well as the work of others. Artists are expert at visual language and visual communication, and in essence are doing research in visual language and image creation frequently the same work as the scientists, but for different reasons.

Artists have an important contribution to make to the new field of scientific visualization. Artists are highly educated and innovative intellectuals, in addition to being organizers of visual information. And scientific visualization artists function beyond illustrators, applying their creativity to new information. The National Science Foundation report last year describes this.

Donna Cox of NCSA - National Center for Supercomputing Applications - is setting an excellent example. She and her colleagues have pioneered the renaissance teams, which bring together artists and scientists in joint efforts in scientific research, specifically the visual representation of multi- dimensional data. The "Art to the Nth Group" in Illinois is also active in the synthesis of art and science. At the San Diego Supercomputer Center, there is an effort to bring together artists and scientists, including Holiday Horton, who is working with scientists on various visualization projects, and myself as well.

I am currently collaborating with Dr. Lynn Teneyck, a crystallographer, on a research project in interactive stereoscopic animation, funded by the National Science Foundation. I just talked a bit and showed you about my work this summer at the Jet Propulsion Lab. This experience was a delight for me on many levels, since I felt I was helping science while at the same time educating myself.

Contrary to popular opinion, research fine artists and research fine scientists share a great many concerns and sensibilities, and are able to truly enhance each other's work in profound ways. There is a natural link between the two, a natural desire to share ideas, vision and expertise. And scientific visualization is an area where I feel the artist as intellectual, the artist as interpreter of complex data and concepts is well suited and integrates smoothly.

Fine artists are also good and necessary role models for the next generation of computer graphics professionals. Let us not forget that education is an important and respectable profession. Not only is this a way to give back to a society in a world which has provided for us, but it is also a way for us to pursue unbeholden except to our highest ideals the purest goals of our creative minds. For many artists intellectual freedom is worth more than the difference in pay scales between various jobs. Further, to ensure the longevity of the field, which ultimately will sustain each and everyone of us, it is vital that the field continue to transform itself in tandem with society. Since artists are also the mirror of our time and the conscience of our culture, artists are in a way a shortcut to the sometimes elusive knowledge about society.

But be aware that the truth is sometimes painful and that the predictions of visionaries are confirmed only in the future. That at the time of invention a new work or idea may not be immediately valued. It may seem worthless, but actually be worth a million. Have the courage of your convictions and you will probably not be disappointed.

Even if you do want to do commercial work because it seems guaranteed, keep in mind that popular culture is based on change - always a new look. The best way to be remembered is to innovate, not imitate. By refining your personal look, you become more unique and therefore more marketable. The very best designers are also fine artists.

Keep up your dreams and your integrity. If you are a good artist, you will have many opportunities. You can choose according to your value system, and you may even be able to create a more compatible job for yourself than you even imagine possible. For example, study a company or environment. Figure out how your expertise can enhance and benefit it, and make a proposal. You may be surprised with the results. Realize that our time on the planet is limited, that time is our only hard currency, that no matter how much money we have we cannot buy back the time that is gone. Weigh your choices carefully and choose the path that passes what I call the "80-year-old test". Will you be proud of what you did with your life when you're 80 and looking back over it? Anyway, that's what I have to say.

\section{Moderator \\ Rachel Carpenter Cinematrix}

Now I know we've taken a little bit of time here, and so I want to remind you about the breakout room, which is going to be in $J$. We do have time for some questions. We don't have to be out of here until 3:15. There are mikes around the room and I will try to see you if you have a question for any of us - for Claire, John, Peter or Vibeke, or myself, Rachel - go to the microphones and I will try to be systematic about it. Are there any questions? Over there? Yes?

Q. I've got one here. (INAUDIBLE - NO MICROPHONE)

CARPENTER: I would like to ask you to first to clarify for what.

Q. For (INAUDIBLE - NO MICROPHONE)

DERRY: I think the main objective is to come into contact with the people who you can communicate with. There are probably. I don't know what your environment is like. But there are researchers at various industries - not just universities. But a university is a great place to find these people. And that's certainly been the resource that I've sought. Q. How about for the rest of you? You talked about you're a little more commercial. California - are we talking about California as the hub of the planet here?

BARRY: I was raised in Sunnyvale, California, right in the heart of Silicon Valley, and I think that it certainly did impact how I developed as an artist, how I was able to be logical and creative at the same time. It was okay because everyone on my block was an engineer growing up. I didn't know until I was about 12 that everyone's father wasn't an engineer.

So being in a hub of technology like that, certainly as an artist growing up, definitely made me not afraid of math and science.

DERRY: I think for myself too - I'm from Nebraska. Most people know Nebraska to be that wide spot in the middle that you drive through on your way to either side. The first intrusion for me into computer graphics was I think NCGA or SIGGRAPH five or six years ago. Once I saw that I realized - I knew I wanted to get involved with it, and I had to figure out a way how and it became apparent to me anyway that the Bay Area or Northern California is one of the hot beds of computer 
graphics. There are several of those hot beds around the country, but for me, moving to the Bay Area was one way to get close to all of the resources and other people that were involved in it. So for me it required a physical relocation.

DERRY: A lot of it will have to do with applications. Well, obviously, video, Southern California is probably more appropriate. We're graphic design, San Francisco and New

York. Advertising, New York. So application would have a lot to do with it as well. But it certainly isn't the way it was five years ago. There's a lot of access to education now. Seven years ago it was MIT, NYIT and a couple of other technological schools.

Q. How does one find out about the different schools to go to? CARPENTER: You can refer to that Volume 23, that I was telling you about before, of the ACM, go to the education booth, and the list of schools there. You can even write letters to people of what you're interested in. Is there another question in the center? Front center?

Q. My question is for Peter. He's talked about having difficult clients and a sign-off sheet. Is there a possibility of getting that sign-off sheet or copy that sign- off shcet?

CONN: Yes, if you see me afterward, I'll get you a copy.

CARPENTER: Is there a question in the back center?

Q. Yes, there is. I tend to be - I'm working with Macromind animation product, and I've come out from a perspective of a frustrated artist-programmer, and so I tend to from my experience of being within this animation company, is really my first real interaction with an artist being at my side and actually using the product simultaneously as I'm programming it. So I would like some feedback as how soon should I really start bringing in an artist onto product design and what would - and if I was going to hire an artist, what would I - what kind of background should I be looking at and what as I as a computer scientist should have in order to elevate myself as a better artist or a better builder of tools for artist?

DERRY: I'd say right away, bring the artist in on day one. I work at Time Arts. We develop software tools and part of my role there is kind of be an in-house artist. It's been amazing to work with programmers. They'll come up with genius level tools or ideas about how to manipulate an image, but generally where they sometimes will go a little off from an artist perspective is in the interface of it. Claire's example that she showed earlier was one of those. When there's an artist inhouse that can be first of all just right there as a direct feedback to test out the tool, that's very valuable to the programmer. Several things that I've worked on - I mean they were just one degree off of being a really great tool, and it just took an artist to sit and talk with the programmer about their ideas and realize that a little bit of slight changes could make that tool exactly what an artist would want.

Later on it got to the point where I could actually come up with tools, and having kind of a clear understanding of what goes on underneath the hood, you can start to work more directly with the programmers to shape tools together. So to me, the artist is a very important - if you're going to design tools for artists, you better have artists designing them.

CARPENTER: Okay, I think there's another question on the side here.

Q. I have a question for Ms. Sorensen. This is a question I'd like to ask one of the visualization, scientific visualization panels of tomorrow. I've heard what comes down to two different points of view I think, on the role of the visual artist in scientific visualization. So I'd like to pose this to you as somebody who has worked in that field in an academic context.
What I've heard is both a "renaissance team" concept and something that's counter to that, as far as eliminating the need for a renaissance team by putting all of the software tools directly into the hands of the artist - I mean, into the scientist - and that would seem to me to somewhat the diminish the role of the artist in working directly in the creation and exploration of images for scientific visualization, and I'd like to, I guess, ask you how you see the role - how you see the role of the artist within a scientific visualization context - increasing or diminishing - given those two points of view.

SORENSEN: Well, considering how much there is to grow, it can't help but increase and grow. And I think that considering the level of education of many of the artists their role is not entirely defined and limited at this time. I think it's good that scientists, for instance, have a good art background, and try to learn more about visual language and communication and aesthetics so that they're able to take on some of the work that artists do. I don't think that's a threat to artists. I think in fact that what the next generation of people will become is kind of artist-scientist, where some artist may learn enough science as well. That's a bit idealistic, I know. But it's certainly not impossible. Educational curricula have to develop to allow for this.

I also think that there are plenty of people who are so focused in whatever discipline they're in that they just find it a better use of their time to collaborate with somebody who has the expertise in the needed field. I think that's going to create a continuing need for artists. I don't think that's going to change all that much, considering the size of the field.

CARPENTER: We have another question front, center. Q. It's a fairly philosophical question, so I expect a philosophical answer. In part you've already answered it. CARPENTER: Could you speak a bit more loudly, please? Q. It's a philosophical question in a way, and it's partially been answered just now. To what extent do you think in the future the role of an artist and a scientist aren't going to be completely separated, but they might come one discipline in itself that integrates the two areas. When is that going to happen? And it's going to happen through education I suppose and what can we do about it?

BARRY: I think all of us being here are doing a lot about it. I do believe it's happening now.

CARPENTER: That's SIGGRAPH.

Q. Everybody still talks about an artist here and a scientist here - as two separate entities, as opposed to one.

SORENSEN: I would just say that I think the best thing is for the two groups to establish constructive dialogue - whether it's through formal education or informal contacts. I think there is so much common - so many common interests that it's such a natural interaction and I like that it's not - there's no one solution. There are many solutions. And I think it's that kind of grass roots widespread movement that's going to accelerate it. So I think it's an inevitable. But it can be accelerated even more by educational programs.

CARPENTER: Is there a question on the side over here? Q. Yes. This is for the whole panel. I'm an engineer and I'm exploring uses for a recently developed technology and the question -is there a need for more realistic input tools in the graphic arts world? For example, the ability to hold a stylus in your hand and that stylus would feel like, act like and emulate an airbrush, so that you could - but instead of depositing paint on paper, you would deposit pixels onto the screen. But as you move the airbrush closer and further away, the pattern changes 
-- just like a real airbrush. Is there an interest from the artist in those types of tools?

DERRY: There definitely is. I think if you walk around the show floor this year, you'll see this is the year of the pressure sensitive tablet. There's some breakthroughs in the technology of using a pressure sensitive tablet, and it's early in its implementation. But our company, among others, have integrated this pressure sensitivity with the paint tools so that they do start to provide a very natural feeling tool to the artist. And it's just at the beginning. I know there are tools on the drawing boards that will allow you to sense rotation and angle and like I say, this is the year of the pressure sensitive tablet, and probably within a couple, three years I would imagine any really high level paint system will have a full pressure sensitive set of tools in it. bit.

So I think you're going to start seeing that happen quite a

BARRY: The main advantage of having something like that is to be able to take advantage of the familiarity that you already have with tools, so that the traditional art tools that you already know how to use, you'll be able to transfer those skills to your computer experience.

I think it will be actually interesting once everything is done on the computer. Where do we go from there when we have special computer tools? That's something that I'm looking at.

CARPENTER: I think we have time for one more question and then we will migrate over to Salon $J$, which I guess is down that way. Yes? Scott? Does anybody know which way is it? Yes - that way. Okay, I think there is another question over here. Yes? No?

Q. Yes. For anyone who would care to answer, I am part of a company; I'm a programmer for a company who's making it aspires to make a tool for people making animations - video animations - and it's my understanding that most of these, the soundtrack comes first and then the video is created to match the soundtrack. I wanted to know, am I mistaken in that impression? Or if not, what are the problems associated with reversing that procedure? Does anyone know?

CONN: Yes. It works both ways. I mean sometimes the soundtrack is first and you work it, and sometimes you postscore something. Actually, the best method is to go back and forth where you do like a rough soundtrack, and then you do your visuals or rough visuals, and then you go and you do more refined soundtrack, and you keep a feedback loop going between the two so they can feed off each other and you get the nicest integration of sound and picture.

CARPENTER: Okay, thank you very much. We need to clear out now. There is another panel following us. 